OPEN ACCESS

Edited by:

Peisong Gao,

Johns Hopkins University,

United States

Reviewed by:

Bernahrd Ryffel,

Centre National de la Recherche

Scientifique (CNRS), France

Omid Akbari,

University of Southern California, Los

Angeles, United States

${ }^{*}$ Correspondence:

Min Liu

699083@bucm.edu.cn

Tieshan Wang

TieshanWang@bucm.edu.cn

${ }^{\dagger}$ These authors have contributed equally to this work

Specialty section: This article was submitted to Immunological

Tolerance and Regulation, a section of the journal

Frontiers in Immunology

Received: 22 July 2020 Accepted: 10 May 2021

Published: 09 June 2021

Citation:

Zheng H, Zhang Y, Pan J, Liu N,

Qin Y, Qiu L, Liu M and Wang T (2021) The Role of Type 2 Innate Lymphoid Cells in Allergic Diseases.

Front. Immunol. 12:586078. doi: 10.3389/fimmu.2021.586078

\section{The Role of Type 2 Innate Lymphoid Cells in Allergic Diseases}

\author{
Haocheng Zheng ${ }^{1 \dagger}$, Yi Zhang ${ }^{1 \dagger}$, Jiachuang Pan ${ }^{1}$, Nannan Liu ${ }^{1}$, Yu Qin ${ }^{2}$, Linghui Qiu ${ }^{3}$, \\ Min Liu ${ }^{1 *}$ and Tieshan Wang ${ }^{2 *}$ \\ ${ }^{1}$ School of Traditional Chinese Medicine, Beijing University of Chinese Medicine, Beijing, China, ${ }^{2}$ Beijing Research Institute \\ of Chinese Medicine, Beijing University of Chinese Medicine, Beijing, China, ${ }^{3}$ Journal Press of Global Traditional Chinese \\ Medicine, Beijing, China
}

Allergic diseases are significant diseases that affect many patients worldwide. In the past few decades, the incidence of allergic diseases has increased significantly due to environmental changes and social development, which has posed a substantial public health burden and even led to premature death. The understanding of the mechanism underlying allergic diseases has been substantially advanced, and the occurrence of allergic diseases and changes in the immune system state are known to be correlated. With the identification and in-depth understanding of innate lymphoid cells, researchers have gradually revealed that type 2 innate lymphoid cells (ILC2s) play important roles in many allergic diseases. However, our current studies of ILC2s are limited, and their status in allergic diseases remains unclear. This article provides an overview of the common phenotypes and activation pathways of ILC2s in different allergic diseases as well as potential research directions to improve the understanding of their roles in different allergic diseases and ultimately find new treatments for these diseases.

Keywords: innate lymphoid cells, allergy, ILC2, asthma, atopic dermatitis, food allergy, allergic rhinitis

\section{INTRODUCTION}

Allergic diseases, including asthma, atopic dermatitis (AD), food allergies, and allergic rhinitis (AR), have caused a substantial public health burden, reduced quality of life, and even led to premature death. In recent decades, with the rapid growth of the global economy, allergic diseases have become one of the most impactful diseases in society. The prevalence of allergic diseases has increased significantly in both developed and developing countries, but the increase is more evident in developed countries (1). The pathogenesis of allergic diseases has long been the focus of immunology research, and the occurrence of allergic diseases is closely related to the immune system. The pathophysiologies of allergic diseases are dominated by IgE-mediated inflammation and the type 2 immune response (2), and type 2 helper T cells (Th2 cells) and type 2 innate lymphoid cells (ILC2s) play roles in the development of the type 2 immune response by releasing cytokines such as IL-4, IL-5, IL-9, and IL-13 (3). In addition, regulatory T cells (Tregs) are very important for maintaining immune tolerance for mucosal barriers, dendritic cells (DCs) are related to the interaction between adaptive and innate immunity, and natural killer cells (NK cells), monocytes, and macrophages play major roles in the occurrence and development of allergic diseases (2). 
Innate lymphoid cells (ILCs) are innate immune cells that are difficult to identify due to the lack of cell surface lineage markers. ILC subtypes correspond to T cell subtypes and can be divided into five types, namely, NK cells, ILC1s, ILC2s, ILC3s, and LTi. There is a mirrored correlation between ILCs and T cells. NK cells correspond to CD8+ T cells, and Th1, Th2, Th17 cells correspond to ILC1s, ILC2s, and ILC3s. The related ILC and T cell subgroups have similar functions and are subject to similar regulatory pathways (4). ILC2s, corresponding to Th2 cells in adaptive immunity, are highly involved in many diseases, such as allergic diseases and diabetes, and are specifically correlated with inflammation, metabolism, tissue repair, and nervous system regulation (5).

ILC2s are tissue-resident cells that are predominantly distributed in mucosal tissues such as lung, small intestine, skin, and adipose tissue. ILC2s play essential roles in allergic diseases and in the development of type 2 inflammation. Although ILC2s are present in low numbers in various, they are uniquely indispensable for a variety of allergic diseases because they rapidly enhance type 2 inflammation (3). Understanding the role of ILC2s in different allergic diseases is of great significance for better studying the relationship between allergic reactions and the immune system.

Neither human nor mouse ILC2s express lineage markers, but ILC2s in the normal physiological state express surface molecules such as CD45, CD90, C-kit, Thy-1, and MHC-II. ILC2s in the active state can express KLRG1 and ST2 at high levels according to their tissue location and activity status $(4,6)$. It is worth noting that ILC2s also have memory functions, as mice stimulated with TSLP or IL-33 showed an increased number of ILC2s for nearly 4 months and could react more quickly after the next antigen stimulation (7).

\section{INITIATION OF THE ILC2 RESPONSE DURING ALLERGIC REACTIONS}

Compared with the typical allergic response mediated by $\mathrm{T}$ cells and B cells, the ILC2-mediated response is faster and independent of antigen stimulation. ILC $2 \mathrm{~s}$ can further aggravate local inflammation and the immune response by releasing numerous cytokines that directly act on mucosal epithelia, blood vessels, and nerves or promote the responses of T cells and DCs. However, the activation of ILC2s is strongly correlated with the microenvironment and cell-to-cell signals. Cytokines, including IL-25, IL-33, TSLP, IL-2, IL-9, and IL-7, are necessary for the activation, proliferation, and maintenance of ILC2s (Figure 1) (6).

The major factors regulating ILC2s can be divided into three categories: IL-25, IL-33 and TSLP are major stimulating factors that are secreted by mainly epithelial cells to activate ILC2s; "IL2, IL-4, IL-7, IL-9, TL1A, GITRL, etc. are survival factors, or socalled costimulators, that maintain the basic functionality of ILC2s; and other mediators that include lipid mediators (PGD2, LTD4), nervous peptides (neuromedin U (NMU), vasoactive intestinal peptide (VIP)), hormones ( $\beta$-adrenaline), and the ILC2 inhibitory factor cluster (IL-10, TGF-b).

\section{Epithelial-Derived Cytokines}

IL-25 and IL-33 are well-described signals that lead to a type 2 immune response and induce the differentiation of ILC2s. Both IL-25 and IL-33 can induce ILC2s to secrete IL-5 and IL-13 via the NF- $\kappa$ b or MAPK pathway $(8,9)$. Unlike the reliance of T cells on antigen peptide presentation for full activation, ILC2s can be activated directly by IL-33 in a state that has not been stimulated by antigens. However, mouse ILC2s hardly respond to IL-33 stimulation without costimulators (10). Studies have revealed that peroxisome proliferator-activated receptor- $\gamma(\operatorname{PPAR} \gamma)$ is a member of the nuclear receptor superfamily, which regulates the transcription of target genes after ligand activation. The IL-33 stimulation of ILC2s results in high PPAR $\gamma$ expression on the cell surface, upregulation of the IL-33 receptor ST2, and promotion of the downstream release of IL-5 and IL-13. Therefore, a positive feedback loop exists between IL-33-ST2 signal transduction and PPAR $\gamma$ in the regulation of ILC2 activation (11). IL-25-induced ILC2s (KLRG1hiST2-ILC2s, also called inflammatory ILC2s or iILC2s) are functionally different from IL-33-induced ILC2s (KLRG1 intST2+ ILC2s, also called natural ILC2s or nILC2s) (12), their effects are not completely independent. IL-33 can promote the production of iILC2s by inducing the upregulation of tryptophan hydroxylase 1 (TPH1) expression (13). ilLC2s can develop into nILC2-like cells and ILC3-like cells, and iILC2s can traffic from the intestine to the lung depending on the S1P protein $(12,14)$. Besides, IL-33 is more effective than IL-25 in airway diseases and AD (15). Other ILC2 subtypes, such as Thy-1+Sca-1+IL-18R+ST2-C-Kit- ILC2s, can produce IL-5 and IL-13 after in vitro stimulation to stimulate IgE production by B cells (16), and CD103+ ILC2s (dermis ILC2s) mainly reside in the skin (17). In addition, ILC2s selectively express different cytokine receptors in different tissues. ILC2s mainly express IL-33R in lung and adipose tissue, while ILC2s in the intestine mainly express IL-25R and skin ILC2s express IL-18R. In bone marrow, most ILC2s express both IL-33R and IL-25R, and a few ILC2s express IL-33R, IL-25R or IL-18R receptors (18).

\section{Survival and Activation Factors}

Survival factors, or so-called costimulators, are necessary for maintaining the normal physiological function of ILC2s, and a lack of survival factor signals leads to their dysfunction. Survival factors include two main families, the common $\gamma$ chain family and the TNF superfamily. The common $\gamma$ chain family, including IL-2, IL-7, and IL-9, comprises regulatory factors necessary for ILC2 survival, development, and maintenance; the TNF superfamily, including TL1A and GITRL, is necessary for ILC2 proliferation and for their ability to release type 2 cytokines (6). The activation of ILC2s is closely related to the presence of IL-2 and IL-7, as mouse ILC2s can be activated only in the presence of IL-2 and IL-7 $(19,20)$, and human ILC2s can be activated only in the presence of IL-2 (21). In addition, IL-2 allows ILC2s to selfrelease IL-9 (22), and IL-9 signals are critical for the survival of ILC2s (23). IL-2-mediated ILC2 activation has been described in the lung, mesenteric lymph nodes (MLNs), spleen, and skin (17, $24,25)$. It should be noted that ILC2s can still be activated in 


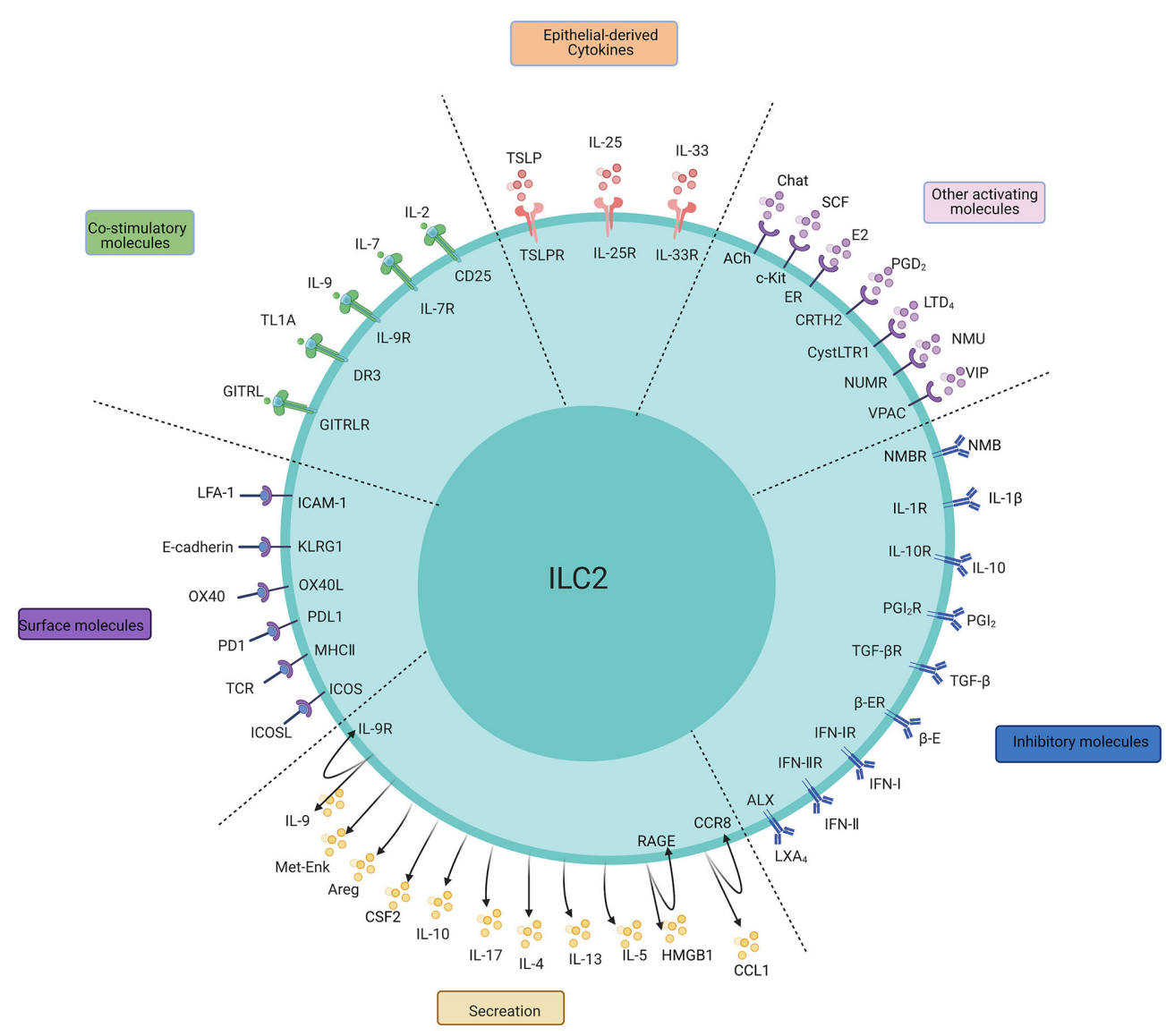

FIGURE 1 | The main regulatory factors, surface molecules, and secretion of ILC2s. The PMIDs of relative articles: IL-1ß: 32086822; IL-25:20023630,22079492; IL-33:21909091,23810766; TSLP:22425247,26129648, 29296700; IL-2:26595888; IL-7:24388011; IL-9:21983833; TL1A:24220298,24368564; GITRL: 29427641; E2:32648964; PGD2:24388011,31900341; LTD4:23688412; NMU:28869974; NMB: 32807943;SCF: 30617299;VIP:24037376; E-cadherin:24323357; OX40/ OX4OL:31470268; PD1:27749818; MHC-II:31320835; ICOS:25769613; IL-4:26883724; IL-9:21983833; IL-10:29196657; IL-17:29625134; Areg:26243875; MetEnk:25533952;|L-10:29196657; TGF-ק:25539814; IFN-I, IFN-II:26595888,26092469,26595887,26425820; PGI2, PGE2:26378386; $\beta$-adrenergic receptor:29496881; LXA4:23447017; CCL-1: 31537642; HMGB1: 32658914, 31937554.

Rag-/- mice infected with N. brasiliensis, which suggests the diversity of IL-2 sources (26). Similarly, TL1A and IL-9 are essential for maintaining the activity of IL-25-induced and IL33 -induced ILC2s $(22,27,28)$. However, in recent years, some researchers have reported that IL-7 may not be a necessary molecule for ILC2 development (29), and the importance of IL-7 in ILC2 development and activation needs to be further assessed. Stem cell factor (SCF) is also a key cytokine involved in the activation of ILC2s that binds to the receptor c-Kit on ILC2s and further amplifies the stimulatory effect of IL-25 on ILC2s to promote the release of downstream cytokines (30).

High-Mobility Group Box 1(HMGB1) is a late inflammatory mediator associated with sepsis, malignancy, and immune disease. HMGB1-dependent receptor for advanced glycation end products (RAGE) induces ILC2 expansion after hemorrhagic shock (HS), promotes ILC2 proliferation and promotes ILC2 survival by attenuating mitochondrial-mediated apoptosis. Type 2 cytokine secretion and eosinophil infiltration caused by ILC2 dilatation in the lung lead to lung injury after HS, and lack of HMGB1-RAGE signaling can reduce ILC2-induced type 2 inflammation (31). Besides, the activation of HMGB1-RAGE signaling pathway in ILC2 leads to an increase in the number of ILC2s secreting IL-13 and remodeling of the airway smooth muscle (ASM) (32).

In addition, many surface molecules and transcription factors are related to the activation of ILC2s. Airway epithelial cells infected by respiratory syncytial virus (RSV) can induce the production of uric acid, IL-33, TSLP and CCL2, the elevated level of uric acid further promotes the expression of innate cytokines, especially IL-1, by AECs and macrophages. Among these factors, CCL2 recruits monocytes, antigen-presenting cells (APCs) and Th2 cells to the lung, while IL-33, TSLP and IL-1 $\beta$ recruit and activate ILC2s (33). The CCL1/CCR8 autocrine signaling loop can regulate ILC2-mediated type 2 immunity and lead to infection resistance in worms, representing a newly discovered chemokine receptor-dependent mechanism (34). ICAM-1 is necessary for the development and function of ILC2s depend on ERK-GATA3 pathway. ICAM-1 deficiency leads to downregulation of the GATA3 protein, thereby resulting in 
ILC2 functional defects (35). ILC2s activated by IL- 33 significantly express LFA-1 and the intercellular adhesion molecule-1 (ICAM-1), the receptor of LFA-1. LFA-1 significantly promote the homing of ILC2s to the lung, and ICAM-1 deficiency significantly downregulates the levels of proinflammatory cytokines such as IL-5, IL-9, and IL-13 (36).

\section{Transcription Factors}

RANK-L, the ligand of NF- $\kappa B$, is mainly expressed in Th2 cells and CXCL16+ APCs in nasal polyps (NPs). The ligand of chemokine receptor 4 (CCR4) could recruits ILC2s and RANK-L+ cells into the NP and promotes the production of type 2 cytokines in ILC2s through a RANK-L-mediated pathway (37). In addition, c-Myc is a basic helix-loop-helix transcription factor mainly responded to IL-33, IL-25 and TSLP, which is closely related to the activation and pathogenicity of ILC2s in vivo. The activation of ILC2s results in the upregulation of c-Myc expression, which leads to proliferation and cytokine production of ILC2 (38). The AP-1 superfamily basic leucine zipper transcription factor, activating transcription factor-like (BATF) potentially regulates ILC2s. BATF defects cause selective damage to ilLC2s in response to IL-25, are the early sources of IL-4 and IL-13 and serve as early guardians of mucosal barrier integrity (39). Runx proteins are a family of transcription factors necessary for many biological processes, and all Runx proteins require heterodimer formation with Subunit b of core binding factor (Cbf $\beta$ ) (40). With the study of transcription factor Runx, the vital role of Runx in ILC2 proliferation and function has been recognized. The stimulation of Runx protein prevent ILC2 from overactivation which could inhibit the emergence of exhaustedlike ILC2s during Allergic Inflammation (41).

\section{Lipoproteins}

Lipoproteins, such as prostaglandins (PGs) and leukotrienes (LTs), the primary lipid mediators in the early stage of inflammation, are also active regulators of ILC2s. CRTH2 is used to identify human ILC2s, and PGD2, a CRTH2 ligand that is mainly expressed by mast cells, can promote the migration of ILC2s and the secretion of IL-13 $(42,43)$. Activated ILC2s also express high levels of LT receptors, and LTD4 is an effective stimulator of ILC2 activation and IL-5 and IL-13 production (44, 45). Although the secretion of IL- 4 by ILC2s has rarely been reported, the stimulation of LTD4 allows ILC2s to produce IL-4 rather than IL-33 or IL-25 $(44,46)$. LTE4 LTC4 are also involved in the regulation of ILC2s, and LXB4 induces IL-13 production in mouse ILC2s $(45,47)$. Moreover, Group V phospholipase A2 (Pla2g5) is a lipid-generating enzyme that is required for the effects of macrophages on pulmonary inflammation. Macrophage-associated Pla2g5 plays an important role in type 2 immunity by regulating IL-33 induction and free fatty acid (FFA)-driven ILC2 activation (48).

\section{Neural Peptides and Hormones}

ILC2s also have a strong relationship with the nervous system. VIP, a member of the neuropeptide secretin family expressed by intestinal cells, pancreatic neurons and suprachiasmatic nuclei of the brain, costimulates the VPAC2 receptor on ILC2s together with IL-7 and promotes the release of IL-5, inducing the generation and recruitment of eosinophils (49). NUM derived from mucosal neurons plays a vital role in ILC2 activation, proliferation, and secretion of type 2 cytokines. NMU stimulates the NMU receptor on ILC2s, which phosphorylates ERK1/2 and induces the activation of the intracellular $\mathrm{Ca} 2^{+}$-calcineurinNFAT cascade to induce the expression of downstream type 2 cytokines (50). Several studies have shown that type 2 cytokines and alarm factors can modulate neuropeptide release and further regulate the immune system. Interestingly, ILC2s are localized around several pulmonary neuroendocrine cells (PNECs) and regulated by PNECs through calcitonin, thereby stimulating the production of ILC2 factors. PNECs produce calcitonin generelated peptide (CGRP) in combination with IL-7, IL-33 or IL25 , which can stimulate CGRP receptors on ILC2s and induce more IL-5 and IL- 6 production (51). In addition, derivatives of testosterone and estradiol have regulatory effects on ILC2s (52, 53). Basophils can enhance the expression of the neuropeptide neuromedin $\mathrm{B}$ (NMB) receptor in mouse ILC2s, and NMB stimulation can inhibit ILC2-mediated type 2 inflammation (54). Compared with wild-type Esr1-/- mice, those stimulated by Alternaria extract (Alt Ext) exhibited fewer IL-33eGFP+ epithelial cells, reduced IL-33 release, reduced secretion of IL-5 and IL-13 and fewer bronchoalveolar lavage (BAL) eosinophils. It has been suggested that ER- $\alpha$ (Esr1) signaling increases the release of IL-33 and ILC2-mediated airway inflammation (55).

\section{Inhibitory Regulation of ILC2}

ILC2s are downregulated by several inhibitory factors and regulatory $\mathrm{T}$ cells. IL-1 $\beta$, derived from pulmonary macrophages, restricts type 2 inflammation and mucinous cell carcinoma after early rhinovirus infection by inhibiting the secretion of congenital cytokines such as IL-25 and IL-33 by epithelial cells, and this effect may be partially mediated by IL-17 (56). Moreover, IFN-I, IFN-II, and IL-27 can inhibit ILC2s, thereby limiting allergic airway inflammation in mice (57). Several lipid molecules were involved in the downregulation of ILC2, PGI2 and PGE2 are effective inhibitors of ILC2 activation (58), and LXA4 effectively inhibits cytokine production in ILC2s (59). Murine intestinal ILC2s express the $\beta$-adrenergic receptor, and the $\beta$-adrenergic pathway is a cell-intrinsic factor that negatively regulates ILC2 responses by inhibiting cell proliferation and effector functions (60).

Tregs play a key role in the inhibitory regulation of ILC2s, as an increase in Treg numbers leads to a decrease in the production of ILC2 cytokines, with IL-10 and TGF- $\beta$ released by Tregs playing central roles in this process (61). Targeted deletion of ROR $\alpha$ in mouse Tregs led to an exaggerated increase in the number of ILC2s (62). ICOS is an important pathway that is required for the proliferation, differentiation, and proinflammatory effects of ILC2s in various diseases. Tregs can also inhibit ILC2s through ICOSICOS-L, thereby controlling airway inflammation in mice, and the ICOS-ICOS-L pathway is integral to Treg-mediated ILC2 suppression (63-65). In contrast, ILC2-derived IL-4 could block Treg function to promote food allergies (66). Wu et al. also reported that PGD2 can activate ILC2s to release IL-5 through CRTH2, thereby inducing the production of CD $4^{+} \mathrm{CD} 25+$ IL5R $\alpha+$ Tregs (67). At the same time, ILC2s function in autocrine IL-9 
signaling, and IL-9 can reduce Treg cell activation, leading to chronic arthritis. Treatment with IL-9 activated ILC2-dependent Tregs and effectively attenuated inflammation (68). In addition, Treg-dependent immunosuppression is correlated with ILC2 augmentation, and Tregs can induce tumor metabolic reprogramming via the STING/ILC2 axis (69). PD-1 is highly inducible in IL-33-activated ILC2s, PD-1 deficiency converts the ILC2 metabolic process into glycolysis, glutamine catabolism and methionine catabolism, enhances the activation and proliferation of ILC2s induced by IL-33, and regulates the production and survival of cytokines in aILC2s, including IL5, IL-13, IL-9 and CSF2 (70).

\section{FUNCTION OF ILC2S IN ALLERGIC REACTIONS}

ILC2s respond quickly to allergic reactions mainly by secreting type 2 cytokines and other peptides, such as IL-4, IL-5, IL-13, IL9, and amphiregulin (Areg), and by intercellular regulation of the cell-to-cell pathway. ILC2s are tissue-resident cells and can be quickly activated by several epithelial-derived cytokines, which allows ILC2s to release type 2 cytokines in the early stage of antigen sensitization (sensitization phase) (Figure 2).

Several cytokines secreted by ILC2s are involved in crosstalk with other immune cells: IL-13 is involved in the migration of activated DCs and activation of macrophages, and IL-5 is involved in the activation of eosinophils. For instance, the IL33/ST2 axis is associated with bone marrow ILC2s and IL-5dependent eosinophilia. Exposure to protease allergens increases the ST2 expression in bone marrow ILC2s, and the production of a substantial amount of IL-5 increases the number of eosinophils (71). IL-9 is involved in the activation of mast cells and ILC2s themselves. In addition, ILC2-derived IL-13 plays a decisive role in the migration of DCs to lymph nodes, which leads to the differentiation of Th2 cells and to the secretion of antibodies (72).

Crosstalk also exists between the two main innate immune components, complement components and ILC2s. C3a is a major driver of the ILC2-mediated inflammatory response to allergens and IL-33 and can increase and enhance the number and function of ILC2s induced by IL-33 and induce IL-13 and granulocyte-macrophage colony-stimulating factor (GMCSF) to inhibit IL-10 production in ILC2s. For ILC-T cell crosstalk, ILC2s exert antigen-presenting effects through C3a signaling. At the same time, C3a promotes the activation of MHC-IIdependent $\mathrm{T}$ cells, thus promoting the differentiation and proliferation of Th2 cells and further enhancing Th2 immunity (73).

Additionally, Madouri $\mathrm{F}$ et al. found that mice lacking PKC- $\theta$ had reduced ILC2 numbers, Th2 cell numbers, and AHR. Adoptive transfer of ILC2s restored eosinophil influx and IL-4, IL-5 and IL-13 production in the lung tissue as well as TH2 cell activation, demonstrating the vital role of PKC in the crosstalk between ILC2s and Th2 cells (74). ILC2s and Th2 cells, the leading promoters of the type two immune response in natural and adaptive immunity, are reciprocal activators during allergy initiation. Pelly found that ILC2-derived IL-4, which is induced by LTD4, is necessary for Th2 cell differentiation, and the lack of ILC2-derived IL-4 can lead to Th2 cell dysfunction (46). On the other hand, Oliphant reported that ILC2-derived IL-2, rather than IL-4, is essential for Th2 maintenance (24). In the recall phase, $\mathrm{T}$ cell infiltration conversely promotes the activity of ILC2s via the release of IL-2 and IL-4 and via B cells to promote the development of allergic reactions. Activated $\mathrm{B}$ cells release numerous IgE antibodies and bind to FCeR on the surface of mast cells and basophils to enhance allergic responses. PAG1, a transmembrane connexin that affects the signal transduction of $\mathrm{T}$ and $\mathrm{B}$ cell receptors, can promote airway epithelial activation, ILC2 expansion and TH2 differentiation and aggravate the severity of asthma (75).

ILC2s also express several surface markers, such as ICOS ligand, MHC-II, and OX40L, which have broad effects on TH2 cells, B cells, and Tregs. ICOS belongs to the CD28 superfamily, and both human and mouse ILC2s express ICOS and its ligand (ICOSL), which can regulate the function of effector T cells (63). ILC2s play a role in APCs by upregulating MHC-II, regulating the Th1/Th2 balance, and transforming adaptive immunity into a Th2-type response (76). Lung ILC2s may regulate the proliferation and activation of CD4 $\mathrm{T}$ cells induced by RSV through the OX40/OX40L interaction (77). Death receptor 3 (DR3) is involved in inducing naïve and activated ILC2s to produce type 2 cytokines. The latest research shows that IL-33 can induce fat retention and the expression of DR3 in human peripheral blood ILC2s and participate in canonical and/or noncanonical NF- $\kappa \mathrm{B}$ pathways to improve glucose tolerance and regulate the metabolic homeostasis of adipose tissue; thus, IL-33 can be used to treat patients with type 2 diabetes (T2DM) (78). Tumor necrosis factor-like protein $1 \mathrm{~A}$ (TL1A) and the receptor DR3 costimulate T cells and ILC2s and play roles in a variety of autoimmune and allergic diseases. For example, the expression of ROR $\alpha$ in resident T cells in the skin can upregulate the expression of DR3, promote $\mathrm{T}$ cell function, and inhibit allergic dermatitis. Therefore, the $\operatorname{RoR} \alpha$ and TL1a-DR3 pathways can be used as therapeutic targets for allergic dermatitis (62). ILC2s can interact with Tregs through ICOS/ ICOS L and IL-4, thereby inhibiting Treg activity. Tregs can downregulate ILC2 function via TGF-b and IL-10 $(65,66)$.

ILC2s can destroy the integrity of the mucosa by secreting IL13 , thereby making it easier for allergens to enter the stroma through the epithelium (79). However, most ILC2s are associated with mucosal repair. Mucosal barrier dysfunction can lead to the release of epithelial alarm molecules, including IL-33, IL-25, and TSLP, thereby activating ILC2s. In contrast, ILC2s can promote epithelial cell repair by producing Areg. IL-33 can be used to treat intestinal inflammation through the Areg-EGFR pathway (80). The secretion of IL-4 and IL-13 by ILC2s is crucial for the formation of AAMs, which are involved in the repair of epithelial cells (81). In addition, IL-9-mediated ILC2 survival is necessary for maintaining tissue integrity and lung function (23). ILC2s can release IL-9 to prevent epithelial cell apoptosis in mice with sepsis (82). Simultaneously, some researchers have shown that IL-9 secreted by ILC2s has a specific protective effect on 


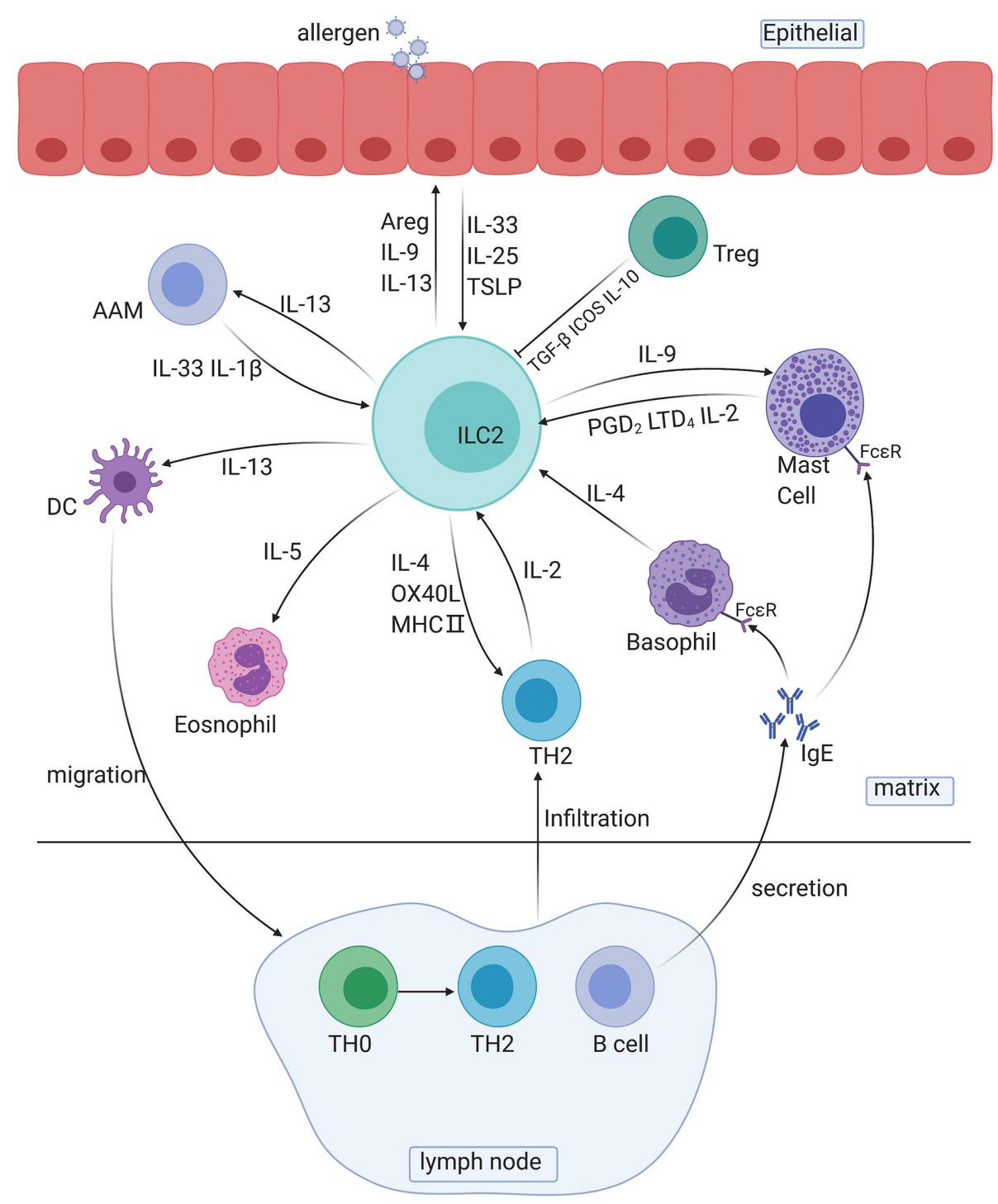

FIGURE 2 | The roles of ILC2s in immune responses. AAM, alternative activated macrophage; DC, dendritic cell; TH cells, T helper cells; Areg, amphiregulin.

inflammation. IL-9 treatment can promote ILC2-dependent Treg activation and effectively reduce inflammation, which may explain the unique role of IL-9 in arthritis (68).

\section{ILC2S IN ALLERGIC ASTHMA}

Chronic airway inflammation commonly presents clinically as AR or chronic rhinosinusitis (CRS) in the upper airway and as asthma in the lower airway (83). A total of $19-38 \%$ of AR patients have concomitant asthma, and a much higher proportion of asthma patients have concomitant AR (84). This indicates that these diseases share some pathophysiological and immunological pathways, in which the type 2 immune response and IgEmediated inflammation play a vital role. ILC2s, as newly identified participants in the innate immune system, have a wide range of effects on these diseases.

The prevalence of asthma has increased by almost $30 \%$ in the past two decades. Over 30 million patients worldwide suffer from it each year, which poses a heavy burden on public health services (85). Asthma is a chronic inflammatory respiratory disease characterized by AHR, type 2 inflammation, and airway remodeling. Classically, Th2 cells play an important role in the development of asthma by releasing type 2 cytokines.

\section{Role of ILC2s in Asthma}

The numbers of both blood ILC2s and bronchoalveolar lavage fluid (BALF) ILC2s were shown to be increased in asthmatic mice, which contributed to the development of experimental asthma via the rapid secretion of IL-5 and IL-13 to aggravate 
lung eosinophilia and mucus production and exacerbate AHR $(86,87)$. In the house dust mite (HDM) mouse model, ILC2deficient mice showed decreased IgE levels (87). In patients with severe asthma patients, the levels of ILC2s in the blood and sputum are increased significantly (88). These results suggest that ILC2s are highly involved in asthma.

ILC2s are the predominant population of ILCs in the lung in the steady state but still represent only a small group of immune cells in the lung (89). The persistence of the mouse asthma model has been proven to be dependent on ILC2s rather than antigenspecific T cells $(20,90)$. In a mouse model of asthma, IL-25induced ILC2s and IL-33-induced ILC2s contributed 50 80\% of the total IL5 and IL-13 production in the lung (91), although stimulation with IL-25 or IL-33 separately did not cause excessive lung reactions (92). It should be noted that different airway allergens may play different roles in the activation of ILC2s. Helfrich found that different airway models and mouse strains exhibited vastly different ILC2 numbers and distribution patterns in the lung and MLNs, suggesting the necessity of using multiple mouse strains to study ILC2 function in asthma (93).

In asthma, after activation by epithelial-derived alarm cytokines, ILC2s promote pulmonary inflammation by secreting type 2 cytokines, including IL- 4 , IL-5, and IL-13, to enhance the contraction of smooth muscle, secretion of mucus, and infiltration of inflammatory cells (94). IL-2 was found to effectively aggravate the inflammatory response in the lungs. The loss of IL-2 was shown to decrease ILC2 function, thereby reducing the lung inflammation caused by asthma in IL-2deficient mice (25). Basophil-derived IL-4 and T cell-derived IL-2 are necessary for establishing rapid allergic reactions mediated by ILC2s (25, 95). In addition, CD127 (IL-7 receptor) is generally considered to be a marker of ILC2s, and some researchers have found that ILC2s can be activated only in the presence of IL-7. However, CD127low ILC2s have also been identified in asthma patients and mice, and it is worth noting that CD127 expression was shown to be decreased after IL-25 stimulation (12). The dependence of ILC2s on IL-7 in asthma and the regulatory mechanism of IL-7 on ILC2 function remain unclear and need further study.

In Rag-/- and WT mice, inhalation of papain caused mucus production, which was alleviated by IL2rg knockout, and mucus production resumed after the adoptive transfer of ILC2s, which indicated the critical role of ILC2s in inducing mucus secretion (96). The enhancement and activation of eosinophils are decisive for increasing airway mucus. LTD4 and papain can potentiate eosinophil and ILC2 proliferation in Rag-/- mice, and a lack of ILC2s leads to a decrease in the number of eosinophils $(20,44)$. Some scholars further verified that IL- 5 and IL-13 released by ILC2s are the key cytokines responsible for eosinophil induction. Lack of ILC2-derived IL-5 and IL-13 leads to a decrease in the number of eosinophils $(97,98)$. These results also corresponded to the early increase in eosinophil numbers found in asthma models and suggest that ILC2s can enhance the activation of eosinophils in the early stage of asthma to produce mucus. At the same time, IL-13 produced by ILC2s could directly affect epithelial and smooth muscle cells, thereby inducing the production of AHR, mucus secretion, and airway remodeling in patients with allergic asthma. Researchers found that H3N1infected Rag-/- mice could still develop AHR, but the AHR response disappeared after the depletion of ILC2s with Thy1.2 (19). ILC2s can produce IL-13 to stimulate the differentiation of macrophages into AAMs and promote AAM accumulation, which can lead to airway inflammation and airway remodeling $(99,100)$.

ILC2s also affect the differentiation of Th2 cells and IgE production by $\mathrm{B}$ cells, which is the key process in the development of asthma. ILC2s stimulate the migration of DCs into MLNs by secreting IL-13 to further promote the differentiation of T cells and B cells (72), and loss of ILC2s results in Th2 cell functional deficiency $(72,88)$. ILC2s can also stimulate the function of B cells through ICOS ligands, which are necessary to enhance airway inflammation and AHR (63). Interestingly, transcriptomic and epigenetic studies of human and mouse ILC2s showed that these cells were positively correlated with genes known to be responsible for asthma susceptibility (including RORA, Smad3, GATA3, IL13, ill8r1, and il1rl1), suggesting that ILC2s are downstream regulators of some susceptibility genes in asthma development (101).

Although ILC2s are thought to induce inflammation in patients with asthma, researchers found that they also protect against inflammation by releasing IL-9. ILC2s could prevent the apoptosis of epithelial cells in subjects with sepsis through the secretion of IL-9, but whether ILC2-derived IL-9 plays an essential role in asthma remains unclear (82). Some researchers discovered a group of new ILC2 subsets that have the ability to produce IL-10 under IL-2 stimulation to further reduce inflammation in the lungs. It is worth noting that IL-2 is also an effective cytokine for inducing the production of IL-9 in ILC2s (22), suggesting that the IL-2-ILC2 axis functions in tissue repair.

Previous research has described the crosstalk between the nervous system and asthma (102). Sui et al. found that PNECs could regulate ILC2s, thus enhancing the allergic reaction in asthmatic mice by releasing neuropeptides (51). Wallrapp et al. have shown that the NUM protein can also enhance allergic inflammation in the lungs by activating ILC2s (103). In addition, Lauriane found that LC2s express the $\alpha 7$-nicotinic acetylcholine receptor $(\alpha 7 \mathrm{nAChR})$, which is thought to play an antiinflammatory role in several inflammatory diseases. The $\alpha 7 \mathrm{nAChR}$ agonist could decrease ILC2-dependent airway hyperreactivity by downregulating the transcription of GATA3 and NF- $\kappa B$ (104). Given the strong correlation between the nervous system and asthma, the regulatory mechanism of ILC2s and the nervous system in patients with asthma is worthy of investigation.

Steroid therapy is a conventional treatment for asthma, but patients often develop resistance, thus leading to refractory asthma (105). Research shows that patients with severe refractory asthma have significantly higher airway ILC2 levels than those without asthma. Systemic steroids, rather than inhaled steroids, could relieve symptoms and reduce the number of ILC2s (106). In addition, the steroid resistance caused by ILC2s is dependent on TSLP activation, and TSLP- 
induced steroid resistance can be reversed by MEK and STAT5 inhibitors $(107,108)$. These findings provide insights into treatments targeting the TSLP pathway in steroid-resistant patients. Additionally, Ma Suli found that the levels of the membrane molecule OX40L were significantly increased in patients with steroid resistance, and OX40L was shown to be highly expressed in ILC2s (109).

\section{ILC2 Recruitment in the Lung}

Unlike Th2 cells, which reside in lymphatic tissue and mostly migrate to tissues only after activation, ILC2s have been described as tissue-resident cells. Upon the occurrence of inflammation, ILC2s exert local immune effects after stimulation by the corresponding cytokines. However, ILC2s have the potential to translocate from one tissue to another. Huang et al. found that ILC2s could migrate from the intestine through lymphatic channels dependent on the S1P protein, thereby aggravating asthma (14). In addition, LFA-1 can significantly control the recruitment of ILC2s to the lungs, which indicates that it is also involved in the migration of ILC2s to the lungs (36). BATF plays a key role in the migration of IL-25-induced ILC2s, and migratory ILC2s are an important source of IL-4 and IL-13 in the early response stage (39).

\section{ILC2S IN ALLERGIC RHINITIS}

\section{Role of ILC2s in Allergic Rhinitis}

$\mathrm{AR}$ is characterized by IgE-mediated inflammation, which results in increased numbers of Th2 cells and type 2 cytokines in the nasal mucosa (110). Some studies found that after intranasal allergen challenge in cats, the numbers of CRTH $2^{+}$ILC2s in the peripheral blood were increased significantly (111). Peng et al. identified the distribution of ILC2s on the nasal mucosa membrane through immunohistochemistry and found that the number of ILC2s in the nasal mucosa was positively correlated with the AR clinical visual analog scale (VAS) score (112). In contrast, two articles reported that the numbers of peripheral blood ILC2s were not significantly altered in patients with AR and in artemisinin-induced mice $(86,113)$. Additionally, Kato assessed the role of ILC2s in AR by using a ragweed-induced mouse model and found that, compared with that in the PBS group, sneezing either disappeared or became significantly less frequent over time in Rag2-/- mice, suggesting that $\mathrm{T}$ cells, not ILC2s, are central to the development of AR (114). All of these findings indicate that ILC2s are far less important in AR than in asthma, and more reliable evidence is needed to determine how ILC2s are involved in the AR response.

Some studies have focused on the initiation pathway of ILC2s in AR. Allogeneic and autologous Myeloid dendritic cells (MDCs) were shown to activate ILC2s in patients with AR to produce type 2 cytokines and increase GATA-3 signal transduction and transcription factor activation. MDCs promoted ILC2 function in AR patients through the IL-33/ST2 pathway, and $\mathrm{pDC}$ activation inhibited ILC2 function through IL-6 (112). There are several reports of multiple lipid receptors, including CysL1R (LTD4 ligand) and PGD2, that are upregulated in AR patients. Although LTD4 was shown to activate IL-4 production in ILC2s, it should be noted that the levels of IL-4 in the nasal secretions of AR patients were not significantly changed (47). In addition, PGD2 has a chemotactic effect on CRTH2+ ILC2s in the blood of patients with AR and may directly regulate the migration of ILC2s into tissues (113). Whether lipid molecules regulate AR through ILC2s needs to be further investigated. Ozone has been shown to aggravate $\mathrm{AR}$ and asthma by inducing the release of IL-5 and IL13 from ILC2s (115).

It is worth noting that the number of ILC2s in patients with HDM-induced AR was significantly higher than that in those with mugwort-AR (116). The peripheral blood ILC2 content was considerably higher in human pediatric patients with HDM-AR than in those without HDM-AR (117). The possible mechanism underlying this difference is that HDM is more immunogenic than plant-derived allergens, and its sensitization mechanism is presumably different from that of plant-based allergens, such as wormwood pollen (118).

\section{ILC2S IN ALLERGIC DERMATITIS \\ Role of ILC2s in Allergic Dermatitis}

$\mathrm{AD}$ is a multifactorial complex inflammatory skin disease that involves barrier dysfunction and severe itching caused by chronic eczema (119). According to a report published in 2016, the 12month adult prevalence of $\mathrm{AD}$ was $4.9 \%$ in the US, $3.5 \%$ in Canada, and $4.4 \%$ in the EU, with values for individual countries ranging from $2.2 \%$ for Germany to $8.1 \%$ for Italy. Among those countries, the US had the highest incidence rate of severe AD. Dermatitis was reportedly one of the most significant causes of increased years lived with disability (YLD) values and the most prevalent skin condition in China in 2017, with 1.39 million cases being reported, which was increased by $5.05 \%$ compared with that in 1990 (1.32 million) (120).

The pathological process of $\mathrm{AD}$ is characterized by a type 2 immune response and a rapid increase in $\operatorname{IgE}$, which is accompanied by eosinophil infiltration, mast cell activation and involvement of other related lymphocytes in the production of typical type 2 cytokines, such as IL- 4 , IL-5 and IL-13. AD always represents the first step in "atopic march", which leads to other allergic diseases, including asthma and AR. The pathological process of $\mathrm{AD}$ is divided into 3 stages: the nonlesional skin stage, acute lesional stage, and chronic lesional stage. The early stage is initiated by innate immunity, in which ILC2s play an important role. The acute stage is characterized by a noticeable type 2 immune response and inflammation, and the chronic stage mainly involves Th1 inflammation and the infiltration of various inflammatory cells $(121,122)$.

Overexpression of IL-33, IL-25, and TSLP has been observed in patients with $\mathrm{AD}$ (122). However, it should be noted that IL33 may play a more prominent role in the activation of ILC2s in patients with $\mathrm{AD}$, as ILC2s isolated from lesions predominantly responded to IL-33 rather than IL-25 and TSLP. At the same 
time, IL-33 induced ILC2 migration and cytokine production, whereas only TSLP at a high concentration combined with IL-25 induced these phenomena (122-124). IL-33-induced AD in mice relies on ILC2s, which are the primary mechanism responsible for the development of human $\mathrm{AD}$ (124). A clinical trial on etokimab, an IL-33 antibody, for the treatment of $\mathrm{AD}$ also revealed the vital role of IL-33 in mediating human AD (125). It has also been indicated that nILC2s but not iILC2s mainly inhabit healthy human skin (122). An experiment utilizing transgenic mice with a high level of skin-specific IL-33 indicated that the mice exhibited spontaneous dermatitis with AD-like inflammation (126). In contrast, the depletion of ILC2s via the transplantation of bone marrow from ROR $\alpha$-deficient mice into IL33tg mice (a type of transgenic mouse overexpressing IL-33) reduced IL-33-induced AD-like inflammation (127). A study performed in 2019 proved that eliminating $\mathrm{T}$ and $\mathrm{B}$ cells in IL33tg mice did not reduce symptoms, such as skin inflammation and increased numbers of ILC2s and type 2 cytokines (124).

Of note, CD103+ ILC2s, unique to the skin, were described as dermal ILC2s (dILC2s), which are distinct from other ILC2 subgroups (17). This group of ILC2s was shown to promote the activation of mast cells, the recruitment of eosinophils and the production of IL-5 via IL-2 treatment (17). The dermal ILC2mediated expansion of DCs involves the expression of CCL17, which is vital for the TH2 memory cell response $(128,129)$. This illustrates that ILC2s are critical for orchestrating an efficient localized memory $\mathrm{TH} 2$ cell response in collaboration with tissueresident DCs. Simultaneously, these results demonstrate the presence of various phenotypes of ILC2s in the skin, but their contributions to $\mathrm{AD}$ need to be further assessed.

High numbers of basophils were detected in subjects with $\mathrm{AD}$ like inflammation, accompanied by ILC2 proliferation and upregulation of IL-5 and IL-4 (124). Basophils were also shown to be involved in the exacerbation of $\mathrm{AD}$-like inflammation and activation of ILC2s via IL-4. After activation by basophils, ILC2s not only clearly accumulate but also enhance the expression of CCL11, IL-5, IL-9 and IL-13, which further leads to the accumulation of eosinophils and promotes other inflammatory responses in subjects with allergic diseases $(124,130)$. Cysteinyl leukotrienes (CysLTs), including LTC4, LTD4 and LTE4, are also effective molecules for moderating ILC2s and promoting the process of AD. Among the three LTs, LTE4 may have the greatest effect on ILC2 proliferation and induce the production of IL-4, IL-5 and IL-13 $(44,131)$. Moreover, ILC2s can regulate T cells through MHC-II, with only $3 \%$ of ILC2s in the skin and 50\% of ILC2s in the skin-draining lymph nodes of mice expressing MHC-II $(129,132)$.

It should be noted that in the BALB/C mouse $\mathrm{AD}$ model induced by MC903, IL-25 had a greater effect on activating ILC2s than IL-33, but it was less important than TSLP. In contrast, TLSP was more vital than IL-33 and IL-25 in the C578BL/6 murine model (122). AD can be simulated in a variety of mouse models, which have skin symptoms and pathological changes that are similar to those of humans. Although considerable differences exist among each mouse AD model, human skinderived ILC2s primarily respond to IL-33 (122, 123).

\section{Outside-in Hypothesis - Local Inflammation Induced by Skin Disorders}

Filaggrin (FLG), a filament-associated protein that binds to keratin fibers in epithelial cells, is highly associated with $\mathrm{AD}$ development. Seventy-three percent of AD patients carry at least 1 FLG null mutation, and FLG-deficient mice present symptoms of spontaneous skin lesions (133). Gene-edited mice were generated to simulate FLG deficiency in humans, and the frequency of ILC2s was increased in the lesions of FLGdeficient mice $(134,135)$. In addition to FLG, the proteins filaggrin-2, hornerin, and the cornified envelope precursor SPRR3 are also linked to the onset of $\mathrm{AD}$, but the mechanism needs to be further studied (136-138). The tight junction proteins between cells and the stratum corneum are skin barriers that prevent the invasion of microorganisms. The absence of epidermal keratins, such as FLG, promotes the binding of microorganisms to the skin and further leads to an inflammatory reaction, which is a major mechanism of $\mathrm{AD}$ development. More than $90 \%$ of $\mathrm{AD}$ patients exhibit lesions with Staphylococcus aureus, while only $5 \%$ of healthy people have Staphylococcus aureus (139). After microorganisms break through the skin barrier, the innate immune system initiates an initial response first, which leads to the activation of adaptive immunity. Additionally, the immune statuses of $\mathrm{AD}$ patients with lesional and nonlesional skin are significantly different. Thus, scientists have proposed that the pathogenesis of $\mathrm{AD}$ is related to epidermal dysfunction caused by genetic mutations, microbial infections, and other factors that are critical drivers of AD. ILC2s, as the predominant producer of type 2 cytokines in the early stage that have MHC-II and Toll-like receptor (TLR) activity, are broadly involved in the response to microorganisms. Damage to epithelial cells leads to the production of alarm factors to activate ILC2s.

\section{Immune Disorder Hypothesis- Immune-Mediated Skin Disorders}

The incidence of $\mathrm{AD}$ is related to not only genetic factors and microorganisms but also endogenous factors, such as diet, pressure and living conditions. Internal factors must exist that regulate the pathogenesis of AD. Some studies found that over $50 \%$ of patients with severe $\mathrm{AD}$ had asthma, $\mathrm{AR}$, or food allergies, suggesting the importance of immune system-mediated skin dysfunction in the pathogenesis of AD (140). IL-4, IL-13, IL-22, and IL-13 can reduce the protein expression of FLG and activate the release of bradykinin $(141,142)$, and the effectiveness of anti-IL-4 and anti-IL-13 in AD treatment shows the importance of the type 2 immune response in humans with AD (143). Moreover, immunosuppressive therapies and immunotherapies, such as steroids, were shown to inhibit the epidermal responses of clinical AD patients (144), suggesting that epidermal dysfunction induced by immune system abnormalities is another mechanism leading to the development of AD. Although ILC2s can repair epidermal damage through Areg, various phenomena suggest that ILC2s are likely key factors that aggravate skin inflammation in $\mathrm{AD}$ patients. However, the specific role and mechanism of ILC2s in epidermal repair and injury still need further exploration. 


\section{ILC2S IN FOOD ALLERGIES}

\section{Role of ILC2s in Food Allergies}

Food allergies are incurable, and allergen-specific IgE antibodies are usually produced, which mediates hypersensitivity. At present, the development of food allergy sensitivity remains poorly understood, but IL-9 is known to induce the release of mucosal tissue mast cells (MMC9), basophils and Th2 cells, and Treg cells play a significant role in this process (145). The intestinal mucosa contains a large number of ILC2s, which promote allergic reactions by releasing IL-4, IL-5, IL-9 and IL13. Scholars have also discovered the important role of ILC2s in the pathogenesis of food allergies (146). In addition, because the ingredients in food are mostly nonself-antigens, the tolerance established by gastrointestinal lymphoid cells such as Tregs is essential, and the reduction or loss of Tregs is a crucial mechanism underlying food allergies.

Food allergies can be divided into two types: IgE-mediated and non-IgE-mediated. In general, DCs and other APCs present antigens to Treg cells to build immune tolerance (147). However, in some cases, the Treg pathway is inhibited or transformed into Th2 cell-activated and IgE-driven immune responses. Sribava found that the ILC2 content in the small intestine was increased in mice with IgE-mediated food allergies (148), and the content of ILC2s was decreased in the small intestine after GATA-1 activity was reduced, indicating the roles of ILC2s and GATA-1 in IgE-mediated food allergies (146). In addition, ILC2s can inhibit the formation of Treg-mediated tolerance by releasing IL4 and further aggravate food allergies (66).

Although food allergies are typically considered to be IgEmediated allergic inflammatory diseases, the association between the IgE concentration and the allergic reaction severity is weak (145). IgE may not be the only factor determining the severity of the disease, as scientists have discovered the importance of IL-25 and IL-33 in food allergies, and IL-33 has been shown to stimulate Th2 cells (149), mast cells and ILC2s to promote the type 2 immune response and IgE release $(150,151)$. In addition, IL-33 was shown to be necessary for the development of a peanut allergy mouse model (152). ILC2s can also release IL-5 and IL-13 under the stimulation of TH2 cells and IL-25, which is vital for the development of eosinophilic inflammation (153).

Animal food allergy models rely on IL-4-mediated immune responses, and IL-4 can decrease Treg-mediated tolerance, which is a critical mechanism of food allergies. It is worth noting that the IL-4 in subjects with food allergies is primarily derived from $\mathrm{CD}^{+} \mathrm{T}$ cells rather than ILC2s, and IL-4 released by ILC2s has no discernible effect on food allergies (154). In ILC-deficient mice, eosinophilic inflammation was significantly weakened, but the Th2 activation, IgE production, and allergic reactions were not significantly changed (154). Correspondingly, Th2 cells rather than ILC2s seemingly play a decisive role in food allergy production. The depletion of CD4 cells or Th2 cells made it difficult for mice to develop an allergic response (153). However, some researchers have reported that ILC2-derived IL-4 is necessary for the development of peanut allergies (154). In addition, the importance of IL-9 in food allergies has been gradually elucidated. MMC9 induction is key to the development of IgE-mediated food allergy sensitivity, which is the main factor mediating intestinal hypertrophy (155). The production and development of MMC9 require stimulation with exogenous IL-9 signals, while ILC2s have the ability to secrete IL-9 (156). It is not clear whether ILC2-derived IL-9 and MMC9 interact with each other and affect food allergies.

\section{Multiple Routes of Food Sensitization}

Epidemiological investigations have revealed significant correlations between food allergies and other allergic diseases, as approximately $50 \%$ of patients with food allergies suffer from $\mathrm{AD}$ (157). Some patients with food allergies present symptoms after the first contact with a certain kind of food, and peanut allergies and the use of skin preparations containing peanut oil are significantly correlated (158). This suggests that sensitization is established via routes other than oral administration. Earlier studies showed that oral, sublingual, nasal contact, and skin contact antigens could induce food allergies and be reproduced by oral administration (159). Skin exposure to allergens promoted the sensitization of mice and activation of Th2 cells to aggravate peanut allergies (149). Subsequently, researchers found that IL-33, but not IL-25 or TSLP, led to significant changes in skin exposed to peanuts, which was sufficient to activate Th2 cells. This indicates that further studying the contribution and mechanism of ILC2 in multiple food sensitization routes is worthwhile.

\section{CONCLUSION}

Although ILCs have been known to exist for only approximately one decade, their role in the immune system is increasingly valued. As mirrors of TH2 cells, ILC2s play a pivotal role in the type 2 response, especially in allergic diseases. As indicated in the current research, ILC2s seemingly play a more important role in asthma and $\mathrm{AD}$ than in $\mathrm{AR}$ and food allergies, and there are few studies on ILC2s in AR and food allergies. Therefore, substantial evidence needs to be collected to assess the role of ILC2s more clearly.

Compared with TH2 cells, ILC2s are much more involved in the early allergy stage, especially in the induction of eosinophilia. ILC2s can be activated without antigen presentation and thus play a unique role in allergic diseases. ILC2s respond more quickly and have a better recognition ability than other cells. IL-33 induces ILC2s to produce $80 \%$ of the IL- 5 and IL- 13 found in the lungs. ILC2s, to some extent, make up for some of the regulatory functions of $\mathrm{TH} 2$ cells in the immune response. In addition, the normal function of ILC2s requires support from other cells via the secretion of IL-2, IL-7, and IL-9. In short, the ILC and adaptive immune systems play complementary roles in the development of allergic diseases.

Current research on ILC2 subtypes remains incomplete. Although some scientists have confirmed the existence of two major ILC2 subtypes, nILC2s and iILC2s, whether more functional subtypes exist and the roles of ILC2s in allergies still need to be determined. In addition, allergic disease treatments based on the ILC2 axis offers a new approach to the discovery of 
allergy drugs. It is imperative to better understand the basic functions, distributions, and classifications of ILC2s and to further explore the relationships between ILC2s and other immune cells, which will enable us to comprehensively understand allergic diseases.

\section{AUTHOR CONTRIBUTIONS}

Our article takes the opinions of allergists in different fields in order to provide an accurate approach to the current progress and research direction of several allergic diseases. $\mathrm{HZ}$ is

\section{REFERENCES}

1. Stróżek J, Samoliński BK, Kłak A, Gawińska-Drużba E, Izdebski R, KrzychFałta, et al. The Indirect Costs of Allergic Diseases. Int J Occup Med Environ Health (2019) 32(3):281-90. doi: 10.13075/ijomeh.1896.01275. E.

2. Barnes PJ. Pathophysiology of Allergic Inflammation. Immunol Rev (2011) 242(1):31-50. doi: 10.1111/j.1600-065X.2011.01020.x

3. Lloyd CM, Snelgrove RJ. Type 2 Immunity: Expanding Our View. Sci Immunol (2018) 3(25):eaat1604. doi: 10.1126/sciimmunol.aat1604

4. Vivier E, Artis D, Colonna M, Diefenbach A, Di Santo JP, Eberl G, et al. Innate Lymphoid Cells: 10 Years on. Cell (2018) 174(5):1054-66. doi: 10.1016/j.cell.2018.07.017

5. Klose CS, Artis D. Innate Lymphoid Cells as Regulators of Immunity, Inflammation and Tissue Homeostasis. Nat Immunol (2016) 17(7):765-74. doi: 10.1038/ni.3489

6. Kabata H, Moro K, Koyasu S. The Group 2 Innate Lymphoid Cell (ILC2) Regulatory Network and its Underlying Mechanisms. Immunol Rev (2018) 286(1):37-52. doi: 10.1111/imr.12706

7. Martinez-Gonzalez I, Mathä L, Steer CA, Ghaedi M, Poon GF, Takei F. Allergen-Experienced Group 2 Innate Lymphoid Cells Acquire Memorylike Properties and Enhance Allergic Lung Inflammation. Immunity (2016) 45(1):198-208. doi: 10.1016/j.immuni.2016.06.017

8. Wong CK, Li PW, Lam CW. Intracellular JNK, P38 MAPK and NF-kappaB Regulate IL-25 Induced Release of Cytokines and Chemokines From Costimulated T Helper Lymphocytes. Immunol Lett (2007) 112(2):82-91. doi: 10.1016/j.imlet.2007.07.002

9. Liew FY, Girard JP, Turnquist HR. Interleukin-33 in Health and Disease. Nat Rev Immunol (2016) 16(11):676-89. doi: 10.1038/nri.2016.95

10. Koga S, Hozumi K, Hirano KI, Yazawa M, Terooatea T, Minoda A, et al. Peripheral PDGFR $\alpha(+) g p 38(+)$ Mesenchymal Cells Support the Differentiation of Fetal Liver-Derived ILC2. J Exp Med (2018) 215 (6):1609-26. doi: 10.1084/jem.20172310

11. Xiao Q, He J, Lei A, Xu H, Zhang L, Zhou P, et al. PPAR $\gamma$ Enhances ILC2 Function During Allergic Airway Inflammation Via Transcription Regulation of ST2. Mucosal Immunol (2021) 14(2):468-78. doi: 10.1038/ s41385-020-00339-6

12. Huang Y, Guo L, Qiu J, Chen X, Hu-Li J, Siebenlist U, et al. IL-25Responsive, Lineage-Negative KLRG1(hi) Cells Are Multipotential 'Inflammatory' Type 2 Innate Lymphoid Cells. Nat Immunol (2015) 16 (2):161-9. doi: 10.1038/ni.3078

13. Flamar AL, Klose CSN, Moeller JB, Mahlakõiv T, Bessman NJ, Zhang W, et al. Interleukin-33 Induces the Enzyme Tryptophan Hydroxylase 1 to Promote Inflammatory Group 2 Innate Lymphoid Cell-Mediated Immunity. Immunity (2020) 52(4):606-19.e6. doi: 10.1016/j.immuni.2020.02.009

14. Huang Y, Mao K, Chen X, Sun MA, Kawabe T, Li W, et al. S1P-Dependent Interorgan Trafficking of Group 2 Innate Lymphoid Cells Supports Host Defense. Science (New York NY) (2018) 359(6371):114-9. doi: 10.1126/ science.aam5809

15. Barlow JL, Peel S, Fox J, Panova V, Hardman CS, Camelo A, et al. IL-33 is More Potent Than IL-25 in Provoking IL-13-Producing Nuocytes (Type 2 responsible for asthma and food allergies parts, JP is responsible for $\mathrm{AD}$ part, and $\mathrm{YZ}$ is responsible for $\mathrm{AR}$ part. Besides, the else contribution is as follows: Review and Editing: HZ, YQ. Language polish: LQ. Visualization: YZ. Funding acquisition: ML. Supervision: TW. All authors contributed to the article and approved the submitted version.

\section{FUNDING}

This research was funded by National Natural Science Foundation of China (No.81774375).

Innate Lymphoid Cells) and Airway Contraction. J Allergy Clin Immuno (2013) 132(4):933-41. doi: 10.1016/j.jaci.2013.05.012

16. Fukuoka A, Futatsugi-Yumikura S, Takahashi S, Kazama H, Iyoda T, Yoshimoto $\mathrm{T}$, et al. Identification of a Novel Type 2 Innate Immunocyte With the Ability to Enhance IgE Production. Int Immunol (2013) 25(6):37382. doi: 10.1093/intimm/dxs160

17. Roediger B, Kyle R, Yip KH, Sumaria N, Guy TV, Kim BS, et al. Cutaneous Immunosurveillance and Regulation of Inflammation by Group 2 Innate Lymphoid Cells. Nat Immunol (2013) 14(6):564-73. doi: 10.1038/ni.2584

18. Zhu J. Mysterious ILC2 Tissue Adaptation. Nat Immunol (2018) 19 (10):1042-4. doi: 10.1038/s41590-018-0214-z

19. Chang YJ, Kim HY, Albacker LA, Baumgarth N, McKenzie AN, Smith DE, et al. Innate Lymphoid Cells Mediate Influenza-Induced Airway HyperReactivity Independently of Adaptive Immunity. Nat Immunol (2011) 12 (7):631-8. doi: 10.1038/ni.2045

20. Halim TY, Krauss RH, Sun AC, Takei F. Lung Natural Helper Cells are a Critical Source of Th2 Cell-Type Cytokines in Protease Allergen-Induced Airway Inflammation. Immunity (2012) 36(3):451-63. doi: 10.1016/ j.immuni.2011.12.020

21. Mjösberg JM, Trifari S, Crellin NK, Peters CP, van Drunen CM, Piet B, et al Human IL-25- and IL-33-Responsive Type 2 Innate Lymphoid Cells are Defined by Expression of CRTH2 and CD161. Nat Immunol (2011) 12 (11):1055-62. doi: 10.1038/ni.2104

22. Wilhelm C, Hirota K, Stieglitz B, Van Snick J, Tolaini M, Lahl K, et al. An IL9 Fate Reporter Demonstrates the Induction of an Innate IL-9 Response in Lung Inflammation. Nat Immunol (2011) 12(11):1071-7. doi: 10.1038/ ni. 2133

23. Turner JE, Morrison PJ, Wilhelm C, Wilson M, Ahlfors H, Renauld JC, et al. IL-9-Mediated Survival of Type 2 Innate Lymphoid Cells Promotes Damage Control in Helminth-Induced Lung Inflammation. J Exp Med (2013) 210 (13):2951-65. doi: 10.1084/jem.20130071

24. Oliphant CJ, Hwang YY, Walker JA, Salimi M, Wong SH, Brewer JM, et al. MHCII-Mediated Dialog Between Group 2 Innate Lymphoid Cells and CD4 (+) T Cells Potentiates Type 2 Immunity and Promotes Parasitic Helminth Expulsion. Immunity (2014) 41(2):283-95. doi: 10.1016/j.immuni. 2014.06.016

25. Roediger B, Kyle R, Tay SS, Mitchell AJ, Bolton HA, Guy TV, et al. IL-2 is a Critical Regulator of Group 2 Innate Lymphoid Cell Function During Pulmonary Inflammation. J Allergy Clin Immunol (2015) 136(6):165363.e7. doi: 10.1016/j.jaci.2015.03.043

26. Neill DR, Wong SH, Bellosi A, Flynn RJ, Daly M, Langford TK, et al. Nuocytes Represent a New Innate Effector Leukocyte That Mediates Type-2 Immunity. Nature (2010) 464(7293):1367-70. doi: 10.1038/nature08900

27. Meylan F, Hawley ET, Barron L, Barlow JL, Penumetcha P, Pelletier M, et al. The TNF-family Cytokine TL1A Promotes Allergic Immunopathology Through Group 2 Innate Lymphoid Cells. Mucosal Immunol (2014) 7 (4):958-68. doi: 10.1038/mi.2013.114

28. Yu X, Pappu R, Ramirez-Carrozzi V, Ota N, Caplazi P, Zhang J, et al. TNF Superfamily Member TL1A Elicits Type 2 Innate Lymphoid Cells at Mucosal Barriers. Mucosal Immunol (2014) 7(3):730-40. doi: 10.1038/mi.2013.92 
29. Robinette ML, Bando JK, Song W, Ulland TK, Gilfillan S, Colonna M. IL-15 Sustains IL-7R-Independent ILC2 and ILC3 Development. Nat Commun (2017) 8:14601. doi: 10.1038/ncomms14601

30. Fonseca W, Rasky AJ, Ptaschinski C, Morris SH, Best SKK, Phillips M, et al. Group 2 Innate Lymphoid Cells (ILC2) are Regulated by Stem Cell Factor During Chronic Asthmatic Disease. Mucosal Immunol (2019) 12(2):445-56. doi: 10.1038/s41385-018-0117-1

31. Zhang K, Jin Y, Lai D, Wang J, Wang Y, Wu X, et al. RAGE-Induced ILC2 Expansion in Acute Lung Injury Due to Haemorrhagic Shock. Thorax (2020) 75(3):209-19. doi: 10.1136/thoraxjnl-2019-213613

32. Loh Z, Simpson J, Ullah A, Zhang V, Gan WJ, Lynch JP, et al. HMGB1 Amplifies ILC2-Induced Type-2 Inflammation and Airway Smooth Muscle Remodelling. PloS Pathog (2020) 16(7):e1008651. doi: 10.1371/ journal.ppat.1008651

33. Fonseca W, Malinczak CA, Schuler CF, Best SKK, Rasky AJ, Morris SB, et al. Uric Acid Pathway Activation During Respiratory Virus Infection Promotes Th2 Immune Response Via Innate Cytokine Production and ILC2 Accumulation. Mucosal Immunol (2020) 13(4):691-701. doi: 10.1038/ s41385-020-0264-Z

34. Knipfer L, Schulz-Kuhnt A, Kindermann M, Greif V, Symowski C, Voehringer D, et al. A CCL1/CCR8-Dependent Feed-Forward Mechanism Drives ILC2 Functions in Type 2-Mediated Inflammation. J Exp Med (2019) 216(12):2763-77. doi: 10.1084/jem.20182111

35. Lei AH, Xiao Q, Liu GY, Shi K, Yang Q, Li X, et al. ICAM-1 Controls Development and Function of ILC2. J Exp Med (2018) 215(8):2157-74. doi: 10.1084/jem.20172359

36. Hurrell BP, Howard E, Galle-Treger L, Helou DG, Shafiei-Jahani P, Painter JD, et al. Distinct Roles of LFA-1 and ICAM-1 on ILC2s Control Lung Infiltration, Effector Functions, and Development of Airway Hyperreactivity. Front Immunol (2020) 11:542818. doi: 10.3389/fimmu.2020.542818

37. Ogasawara N, Poposki JA, Klingler AI, Tan BK, Hulse KE, Stevens WW, et al. Role of RANK-L as a Potential Inducer of ILC2-Mediated Type 2 Inflammation in Chronic Rhinosinusitis With Nasal Polyps. Mucosal Immunol (2020) 13(1):86-95. doi: 10.1038/s41385-019-0215-8

38. Ye L, Pan J, Liang M, Pasha MA, Shen X, D’Souza SS, et al. A Critical Role for c-Myc in Group 2 Innate Lymphoid Cell Activation. Allergy (2020) 75 (4):841-52. doi: 10.1111/all.14149

39. Miller MM, Patel PS, Bao K, Danhorn T, O’Connor BP, Reinhardt RL. BATF Acts as an Essential Regulator of IL-25-Responsive Migratory ILC2 Cell Fate and Function. Sci Immunol (2020) 5(43):eaat3994. doi: 10.1126/ sciimmunol.aay3994

40. Bone KR, Gruper Y, Goldenberg D, Levanon D, Groner Y. Translation Regulation of Runx3. Blood Cells Mol Dis (2010) 45(2):112-6. doi: 10.1016/ j.bcmd.2010.04.001

41. Ebihara T, Taniuchi I. Transcription Factors in the Development and Function of Group 2 Innate Lymphoid Cells. Int J Mol Sci (2019) 20 (6):1377. doi: 10.3390/ijms20061377

42. Chang JE, Doherty TA, Baum R, Broide D. Prostaglandin D2 Regulates Human Type 2 Innate Lymphoid Cell Chemotaxis. J Allergy Clin Immunol (2014) 133(3):899-901.e3. doi: 10.1016/j.jaci.2013.09.020

43. Oyesola OO, Duque C, Huang LC, Larson EM, Früh SP, Webb LM, et al. The Prostaglandin D(2) Receptor CRTH2 Promotes IL-33-Induced ILC2 Accumulation in the Lung. I Immunol (Baltimore Md 1950) (2020) 204 (4):1001-11. doi: 10.4049/jimmunol.1900745

44. Doherty TA, Khorram N, Lund S, Mehta AK, Croft M, Broide DH. Lung Type 2 Innate Lymphoid Cells Express Cysteinyl Leukotriene Receptor 1, Which Regulates TH2 Cytokine Production. J Allergy Clin Immunol (2013) 132(1):205-13. doi: 10.1016/j.jaci.2013.03.048

45. von Moltke J, O'Leary CE, Barrett NA, Kanaoka Y, Austen KF, Locksley RM. Leukotrienes Provide an NFAT-dependent Signal That Synergizes With IL33 to Activate ILC2s. J Exp Med (2017) 214(1):27-37. doi: 10.1084/ jem.20161274

46. Pelly VS, Kannan Y, Coomes SM, Entwistle LJ, Rückerl D, Seddon B, et al. IL-4-Producing ILC2s are Required for the Differentiation of T(H)2 Cells Following Heligmosomoides Polygyrus Infection. Mucosal Immunol (2016) 9(6):1407-17. doi: 10.1038/mi.2016.4

47. Qin ZL, Peng YQ, Fang SB, Jiang AY, Li CL, Fan XL, et al. CysLT1R Expression on ILC2s and Effects of CysLT1R Antagonist on ILC2 Activity in
Patients With Allergic Rhinitis. Allergy (2020) 75(4):977-81. doi: 10.1111/ all.14117

48. Yamaguchi M, Samuchiwal SK, Quehenberger O, Boyce JA, Balestrieri B. Macrophages Regulate Lung ILC2 Activation Via Pla2g5-Dependent Mechanisms. Mucosal Immunol (2018) 11(3):615-26. doi: 10.1038/ mi.2017.99

49. Nussbaum JC, Van Dyken SJ, von Moltke J, Cheng LE, Mohapatra A, Molofsky AB, et al. Type 2 Innate Lymphoid Cells Control Eosinophil Homeostasis. Nature (2013) 502(7470):245-8. doi: 10.1038/nature12526

50. Cardoso V, Chesné J, Ribeiro H, García-Cassani B, Carvalho T, Bouchery T, et al. Neuronal Regulation of Type 2 Innate Lymphoid Cells Via Neuromedin U. Nature (2017) 549(7671):277-81. doi: 10.1038/nature23469

51. Sui P, Wiesner DL, Xu J, Zhang Y, Lee J, Van Dyken S, et al. Pulmonary Neuroendocrine Cells Amplify Allergic Asthma Responses. Science (New York NY) (2018) 360(6393):eaan8546. doi: 10.1126/science.aan8546

52. Cephus JY, Stier MT, Fuseini H, Yung JA, Toki S, Bloodworth MH, et al. Testosterone Attenuates Group 2 Innate Lymphoid Cell-Mediated Airway Inflammation. Cell Rep (2017) 21(9):2487-99. doi: 10.1016/j.celrep. 2017.10.110

53. Bartemes K, Chen CC, Iijima K, Drake L, Kita H. IL-33-Responsive Group 2 Innate Lymphoid Cells are Regulated by Female Sex Hormones in the Uterus. J Immunol (Baltimore Md 1950) (2018) 200(1):229-36. doi: 10.4049/ jimmunol.1602085

54. Inclan-Rico JM, Ponessa JJ, Valero-Pacheco N, Hernandez CM, Sy CB, Lemenze AD, et al. Basophils Prime Group 2 Innate Lymphoid Cells for Neuropeptide-Mediated Inhibition. Nat Immunol (2020) 21(10):1181-93. doi: 10.1038/s41590-020-0753-y

55. Cephus JY, Gandhi VD, Shah R, Brooke Davis J, Fuseini H, Yung JA, et al. Estrogen Receptor- $\alpha$ Signaling Increases Allergen-Induced IL-33 Release and Airway Inflammation. Allergy (2021) 76(1):255-68. doi: 10.1111/ all.14491

56. Han M, Ishikawa T, Bermick JR, Rajput C, Lei J, Goldsmith AM, et al. IL-1 $\beta$ Prevents ILC2 Expansion, Type 2 Cytokine Secretion, and Mucus Metaplasia in Response to Early-Life Rhinovirus Infection in Mice. Allergy (2020) 75 (8):2005-19. doi: 10.1111/all.14241

57. Doherty TA, Broide DH. Pathways to Limit Group 2 Innate Lymphoid Cell Activation. J Allergy Clin Immunol (2017) 139(5):1465-7. doi: 10.1016/ j.jaci.2016.12.003

58. Zhou W, Toki S, Zhang J, Goleniewksa K, Newcomb DC, Cephus JY, et al. Prostaglandin I2 Signaling and Inhibition of Group 2 Innate Lymphoid Cell Responses. Am J Respir Crit Care Med (2016) 193(1):31-42. doi: 10.1164/ rccm.201410-1793OC

59. Barnig C, Cernadas M, Dutile S, Liu X, Perrella MA, Kazani S, et al. Lipoxin A4 Regulates Natural Killer Cell and Type 2 Innate Lymphoid Cell Activation in Asthma. Sci Transl Med (2013) 5(174):174ra26. doi: 10.1126/ scitranslmed.3004812

60. Moriyama S, Brestoff JR, Flamar AL, Moeller JB, Klose CSN, Rankin LC, et al. $\beta(2)$-Adrenergic Receptor-Mediated Negative Regulation of Group 2 Innate Lymphoid Cell Responses. Science (New York NY) (2018) 359 (6379):1056-61. doi: 10.1126/science.aan4829

61. Krishnamoorthy N, Burkett PR, Dalli J, Abdulnour RE, Colas R, Ramon S, et al. Cutting Edge: Maresin-1 Engages Regulatory T Cells to Limit Type 2 Innate Lymphoid Cell Activation and Promote Resolution of Lung Inflammation. J Immunol (Baltimore Md 1950) (2015) 194(3):863-7. doi: 10.4049/jimmunol.1402534

62. Malhotra N, Leyva-Castillo JM, Jadhav U, Barreiro O, Kam C, O’Neill NK, et al. ROR $\alpha$-Expressing T Regulatory Cells Restrain Allergic Skin Inflammation. Sci Immunol (2018) 3(21):eaao6923. doi: 10.1126/sciimmunol.aao6923

63. Maazi H, Patel N, Sankaranarayanan I, Suzuki Y, Rigas D, Soroosh P, et al. ICOS:ICOS-Ligand Interaction is Required for Type 2 Innate Lymphoid Cell Function, Homeostasis, and Induction of Airway Hyperreactivity. Immunity (2015) 42(3):538-51. doi: 10.1016/j.immuni.2015.02.007

64. Paclik D, Stehle C, Lahmann A, Hutloff A, Romagnani C. ICOS Regulates the Pool of Group 2 Innate Lymphoid Cells Under Homeostatic and Inflammatory Conditions in Mice. Eur J Immunol (2015) 45(10):2766-72. doi: 10.1002/eji.201545635

65. Rigas D, Lewis G, Aron JL, Wang B, Banie H, Sankaranarayanan I, et al. Type 2 Innate Lymphoid Cell Suppression by Regulatory $\mathrm{T}$ cells Attenuates 
Airway Hyperreactivity and Requires Inducible T-Cell CostimulatorInducible T-Cell Costimulator Ligand Interaction. J Allergy Clin Immunol (2017) 139(5):1468-77.e2. doi: 10.1016/j.jaci.2016.08.034

66. Noval Rivas M, Burton OT, Oettgen HC, Chatila T. IL-4 Production by Group 2 Innate Lymphoid Cells Promotes Food Allergy by Blocking Regulatory T-Cell Function. J Allergy Clin Immunol (2016) 138(3):80111.e9. doi: 10.1016/j.jaci.2016.02.030

67. Wu L, Lin Q, Ma Z, Chowdhury FA, Mazumder MHH, Du W. Mesenchymal PGD(2) Activates an ILC2-Treg Axis to Promote Proliferation of Normal and Malignant HSPCs. Leukemia (2020) 34(11):3028-41. doi: 10.1038/ s41375-020-0843-8

68. Rauber S, Luber M, Weber S, Maul L, Soare A, Wohlfahrt T, et al. Resolution of Inflammation by Interleukin-9-Producing Type 2 Innate Lymphoid Cells. Nat Med (2017) 23(8):938-44. doi: 10.1038/nm.4373

69. Domvri K, Petanidis S, Zarogoulidis P, Anestakis D, Tsavlis D, Bai C, et al. Treg-Dependent Immunosuppression Triggers Effector T Cell Dysfunction Via the STING/ILC2 Axis. Clin Immunol (Orlando Fla) (2021) 222:108620. doi: $10.1016 /$ j.clim.2020.108620

70. Helou DG, Shafiei-Jahani P, Lo R, Howard E, Hurrell BP, Galle-Treger L, et al. PD-1 Pathway Regulates ILC2 Metabolism and PD-1 Agonist Treatment Ameliorates Airway Hyperreactivity. Nat Commun (2020) 11 (1):3998. doi: 10.1038/s41467-020-17813-1

71. Boberg E, Johansson K, Malmhäll C, Calvén J, Weidner J, Rådinger M. Interplay Between the IL-33/ST2 Axis and Bone Marrow ILC2s in Protease Allergen-Induced IL-5-Dependent Eosinophilia. Front Immunol (2020) 11:1058. doi: 10.3389/fimmu.2020.01058

72. Halim TY, Steer CA, Mathä L, Gold MJ, Martinez-Gonzalez I, McNagny $\mathrm{KM}$, et al. Group 2 Innate Lymphoid Cells are Critical for the Initiation of Adaptive T Helper 2 Cell-Mediated Allergic Lung Inflammation. Immunity (2014) 40(3):425-35. doi: 10.1016/j.immuni.2014.01.011

73. Gour N, Smole U, Yong HM, Lewkowich IP, Yao N, Singh A, et al. C3a is Required for ILC2 Function in Allergic Airway Inflammation. Mucosal Immunol (2018) 11(6):1653-62. doi: 10.1038/s41385-018-0064-x

74. Madouri F, Chenuet P, Beuraud C, Fauconnier L, Marchiol T, Rouxel N, et al. Protein Kinase C $\theta$ Controls Type 2 Innate Lymphoid Cell and T(H)2 Responses to House Dust Mite Allergen. J Allergy Clin Immunol (2017) 139 (5):1650-66. doi: 10.1016/j.jaci.2016.08.044

75. Ullah MA, Vicente CT, Collinson N, Curren B, Sikder MAA, Sebina I, et al. PAG1 Limits Allergen-Induced Type 2 Inflammation in the Murine Lung. Allergy (2020) 75(2):336-45. doi: 10.1111/all.13991

76. Jiang M, Liu H, Li Z, Wang J, Zhang F, Cao K, et al. ILC2s Induce Adaptive Th2-Type Immunity in Acute Exacerbation of Chronic Obstructive Pulmonary Disease. Mediators Inflamm (2019) 2019:3140183. doi: $10.1155 / 2019 / 3140183$

77. Wu J, Cui Y, Zhu W, Bai S, Zhao N, Liu B. Critical Role of OX40/OX40L in ILC2-Mediated Activation of CD4(+)T Cells During Respiratory Syncytial Virus Infection in Mice. Int Immunopharmacol (2019) 76:105784. doi: 10.1016/j.intimp.2019.105784

78. Shafiei-Jahani P, Hurrell BP, Galle-Treger L, Helou DG, Howard E, Painter J, et al. DR3 Stimulation of Adipose Resident ILC2s Ameliorates Type 2 Diabetes Mellitus. Nat Commun (2020) 11(1):4718. doi: 10.1038/s41467020-18601-7

79. Sugita K, Steer CA, Martinez-Gonzalez I, Altunbulakli C, Morita H, CastroGiner F, et al. Type 2 Innate Lymphoid Cells Disrupt Bronchial Epithelial Barrier Integrity by Targeting Tight Junctions Through IL-13 in Asthmatic Patients. J Allergy Clin Immunol (2018) 141(1):300-10.e11. doi: 10.1016/ j.jaci.2017.02.038

80. Monticelli LA, Osborne LC, Noti M, Tran SV, Zaiss DM, Artis D. IL-33 Promotes an Innate Immune Pathway of Intestinal Tissue Protection Dependent on Amphiregulin-EGFR Interactions. Proc Natl Acad Sci USA (2015) 112(34):10762-7. doi: 10.1073/pnas.1509070112

81. Bosurgi L, Cao YG, Cabeza-Cabrerizo M, Tucci A, Hughes LD, Kong Y, et al. Macrophage Function in Tissue Repair and Remodeling Requires IL-4 or IL13 With Apoptotic Cells. Science (New York NY) (2017) 356(6342):1072-6. doi: $10.1126 /$ science.aai8132

82. Lai D, Tang J, Chen L, Fan EK, Scott MJ, Li Y, et al. Group 2 Innate Lymphoid Cells Protect Lung Endothelial Cells From Pyroptosis in Sepsis. Cell Death Dis (2018) 9(3):369. doi: 10.1038/s41419-018-0412-5
83. Ramakrishnan JB, Kingdom TT, Ramakrishnan VR. Allergic Rhinitis and Chronic Rhinosinusitis: Their Impact on Lower Airways. Immunol Allergy Clin North Am (2013) 33(1):45-60. doi: 10.1016/j.iac.2012.10.009

84. Compalati E, Ridolo E, Passalacqua G, Braido F, Villa E, Canonica GW. The Link Between Allergic Rhinitis and Asthma: The United Airways Disease. Expert Rev Clin Immunol (2010) 6(3):413-23. doi: 10.1586/eci.10.15

85. World Health Organization. The Global Asthma Report 2018. (2018). http: // globalathmareport.org/ [AccessedAugust31, 2018].

86. Bartemes KR, Kephart GM, Fox SJ, Kita H. Enhanced Innate Type 2 Immune Response in Peripheral Blood From Patients With Asthma. J Allergy Clin Immunol (2014) 134(3):671-8.e4. doi: 10.1016/j.jaci.2014.06.024

87. Smith SG, Chen R, Kjarsgaard M, Huang C, Oliveria JP, O'Byrne PM, et al. Increased Numbers of Activated Group 2 Innate Lymphoid Cells in the Airways of Patients With Severe Asthma and Persistent Airway Eosinophilia. J Allergy Clin Immunol (2016) 137(1):75-86.e8. doi: 10.1016/ j.jaci.2015.05.037

88. Gold MJ, Antignano F, Halim TY, Hirota JA, Blanchet MR, Zaph C, et al. Group 2 Innate Lymphoid Cells Facilitate Sensitization to Local, But Not Systemic, TH2-Inducing Allergen Exposures. J Allergy Clin Immunol (2014) 133(4):1142-8. doi: 10.1016/j.jaci.2014.02.033

89. Monticelli LA, Sonnenberg GF, Abt MC, Alenghat T, Ziegler CG, Doering TA, et al. Innate Lymphoid Cells Promote Lung-Tissue Homeostasis After Infection With Influenza Virus. Nat Immunol (2011) 12(11):1045-54. doi: $10.1031 / n i .2131$

90. Christianson CA, Goplen NP, Zafar I, Irvin C, Good JTJr., Rollins DR, et al. Persistence of Asthma Requires Multiple Feedback Circuits Involving Type 2 Innate Lymphoid Cells and IL-33. J Allergy Clin Immunol (2015) 136(1):5968.e14. doi: 10.1016/j.jaci.2014.11.037

91. Klein Wolterink RG, Kleinjan A, van Nimwegen M, Bergen I, de Bruijn M, Levani Y, et al. Pulmonary Innate Lymphoid Cells are Major Producers of IL-5 and IL-13 in Murine Models of Allergic Asthma. Eur J Immunol (2012) 42(5):1106-16. doi: 10.1002/eji.201142018

92. Licona-Limón P, Kim LK, Palm NW, Flavell RA. TH2, Allergy and Group 2 Innate Lymphoid Cells. Nat Immunol (2013) 14(6):536-42. doi: 10.1038/ni.2617

93. Helfrich S, Mindt BC, Fritz JH, Duerr CU. Group 2 Innate Lymphoid Cells in Respiratory Allergic Inflammation. Front Immunol (2019) 10:930. doi: $10.3389 /$ fimmu.2019.00930

94. Tliba O, Deshpande D, Chen H, Van Besien C, Kannan M, Panettieri RAJr. et al. IL-13 Enhances Agonist-Evoked Calcium Signals and Contractile Responses in Airway Smooth Muscle. Br J Pharmacol (2003) 140(7):115962. doi: $10.1038 /$ sj.bjp. 0705558

95. Motomura Y, Morita H, Moro K, Nakae S, Artis D, Endo TA, et al. BasophilDerived Interleukin-4 Controls the Function of Natural Helper Cells, a Member of ILC2s, in Lung Inflammation. Immunity (2014) 40(5):758-71. doi: 10.1016/j.immuni.2014.04.013

96. Halim TY, MacLaren A, Romanish MT, Gold MJ, McNagny KM, Takei F. Retinoic-Acid-Receptor-Related Orphan Nuclear Receptor Alpha is Required for Natural Helper Cell Development and Allergic Inflammation. Immunity (2012) 37(3):463-74. doi: 10.1016/j.immuni.2012.06.012

97. Barlow JL, Bellosi A, Hardman CS, Drynan LF, Wong SH, Cruickshank JP, et al. Innate IL-13-Producing Nuocytes Arise During Allergic Lung Inflammation and Contribute to Airways Hyperreactivity. J Allergy Clin Immunol (2012) 129(1):191-8.e1-4. doi: 10.1016/j.jaci.2011.09.041

98. Molofsky AB, Nussbaum JC, Liang HE, Van Dyken SJ, Cheng LE, Mohapatra A, et al. Innate Lymphoid Type 2 Cells Sustain Visceral Adipose Tissue Eosinophils and Alternatively Activated Macrophages. J Exp Med (2013) 210(3):535-49. doi: 10.1084/jem.20121964

99. Van Dyken SJ, Mohapatra A, Nussbaum JC, Molofsky AB, Thornton EE, Ziegler SF, et al. Chitin Activates Parallel Immune Modules That Direct Distinct Inflammatory Responses Via Innate Lymphoid Type 2 and $\gamma \delta$ T Cells. Immunity (2014) 40(3):414-24. doi: 10.1016/j.immuni.2014.02.003

100. Lee YG, Jeong JJ, Nyenhuis S, Berdyshev E, Chung S, Ranjan R, et al. Recruited Alveolar Macrophages, in Response to Airway Epithelial-Derived Monocyte Chemoattractant Protein 1/CCl2, Regulate Airway Inflammation and Remodeling in Allergic Asthma. Am J Respir Cell Mol Biol (2015) 52 (6):772-84. doi: $10.1165 / \mathrm{rcmb} .2014-0255 \mathrm{OC}$

101. Stadhouders R, Li BWS, de Bruijn MJW, Gomez A, Rao TN, Fehling HJ, et al. Epigenome Analysis Links Gene Regulatory Elements in Group 2 Innate 
Lymphocytes to Asthma Susceptibility. J Allergy Clin Immunol (2018) 142 (6):1793-807. doi: 10.1016/j.jaci.2017.12.1006

102. Undem BJ, Carr MJ. The Role of Nerves in Asthma. Curr Allergy Asthma Rep (2002) 2(2):159-65. doi: 10.1007/s11882-002-0011-4

103. Wallrapp A, Riesenfeld SJ, Burkett PR, Abdulnour RE, Nyman J, Dionne D, et al. The Neuropeptide NMU Amplifies ILC2-Driven Allergic Lung Inflammation. Nature (2017) 549(7672):351-6. doi: 10.1038/nature24029

104. Galle-Treger L, Suzuki Y, Patel N, Sankaranarayanan I, Aron JL, Maazi H, et al. Nicotinic Acetylcholine Receptor Agonist Attenuates ILC2-Dependent Airway Hyperreactivity. Nat Commun (2016) 7:13202. doi: 10.1038/ ncomms 13202

105. Martin RJ, Szefler SJ, King TS, Kraft M, Boushey HA, Chinchilli VM, et al. The Predicting Response to Inhaled Corticosteroid Efficacy (PRICE) Trial. J Allergy Clin Immunol (2007) 119(1):73-80. doi: 10.1016/j.jaci.2006.10.035

106. Nagakumar P, Puttur F, Gregory LG, Denney L, Fleming L, Bush A, et al. Pulmonary Type-2 Innate Lymphoid Cells in Paediatric Severe Asthma: Phenotype and Response to Steroids. Eur Respir J (2019) 54(2):1801-809. doi: $10.1183 / 13993003.01809-2018$

107. Kabata H, Moro K, Fukunaga K, Suzuki Y, Miyata J, Masaki K, et al. Thymic Stromal Lymphopoietin Induces Corticosteroid Resistance in Natural Helper Cells During Airway Inflammation. Nat Commun (2013) 4:2675. doi: $10.1038 /$ ncomms 3675

108. Liu S, Verma M, Michalec L, Liu W, Sripada A, Rollins D, et al. Steroid Resistance of Airway Type 2 Innate Lymphoid Cells From Patients With Severe Asthma: The Role of Thymic Stromal Lymphopoietin. J Allergy Clin Immunol (2018) 141(1):257-68.e6. doi: 10.1016/j.jaci.2017.03.032

109. Ma SL, Zhang L. Elevated Serum OX40L is a Biomarker for Identifying Corticosteroid Resistance in Pediatric Asthmatic Patients. BMC Pulm Med (2019) 19(1):66. doi: 10.1186/s12890-019-0819-5

110. Wise SK, Lin SY, Toskala E, Orlandi RR, Akdis CA, Alt JA, et al. International Consensus Statement on Allergy and Rhinology: Allergic Rhinitis. Int Forum Allergy Rhinol (2018) 8(2):108-352. doi: 10.1002/ alr.22073

111. Doherty TA, Scott D, Walford HH, Khorram N, Lund S, Baum R, et al. Allergen Challenge in Allergic Rhinitis Rapidly Induces Increased Peripheral Blood Type 2 Innate Lymphoid Cells That Express CD84. J Allergy Clin Immunol (2014) 133(4):1203-5. doi: 10.1016/j.jaci.2013.12.1086

112. Peng YQ, Qin ZL, Fang SB, Xu ZB, Zhang HY, Chen D, et al. Effects of Myeloid and Plasmacytoid Dendritic Cells on ILC2s in Patients With Allergic Rhinitis. J Allergy Clin Immunol (2020) 145(3):855-67.e8. doi: 10.1016/j.jaci.2019.11.029

113. Badorrek P, Müller M, Koch W, Hohlfeld JM, Krug N. Specificity and Reproducibility of Nasal Biomarkers in Patients With Allergic Rhinitis After Allergen Challenge Chamber Exposure. Ann Allergy Asthma Immunol (2017) 118(3):290-7. doi: 10.1016/j.anai.2017.01.018

114. Kato Y, Akasaki S, Muto-Haenuki Y, Fujieda S, Matsushita K, Yoshimoto T. Nasal Sensitization With Ragweed Pollen Induces Local-Allergic-RhinitisLike Symptoms in Mice. PloS One (2014) 9(8):e103540. doi: 10.1371/ journal.pone. 0103540

115. Yang Q, Ge MQ, Kokalari B, Redai IG, Wang X, Kemeny DM, et al. Group 2 Innate Lymphoid Cells Mediate Ozone-Induced Airway Inflammation and Hyperresponsiveness in Mice. J Allergy Clin Immunol (2016) 137(2):571-8. doi: 10.1016/j.jaci.2015.06.037

116. Fan D, Wang X, Wang M, Wang Y, Zhang L, Li Y, et al. AllergenDependent Differences in ILC2s Frequencies in Patients With Allergic Rhinitis. Allergy Asthma Immunol Res (2016) 8(3):216-22. doi: 10.4168/ aair.2016.8.3.216

117. Sun R, Yang Y, Huo Q, Gu Z, Wei P, Tang X. Increased Expression of Type 2 Innate Lymphoid Cells in Pediatric Patients With Allergic Rhinitis. Exp Ther Med (2020) 19(1):735-40. doi: 10.3892/etm.2019.8235

118. Lao-Araya M, Steveling E, Scadding GW, Durham SR, Shamji MH. Seasonal Increases in Peripheral Innate Lymphoid Type 2 Cells are Inhibited by Subcutaneous Grass Pollen Immunotherapy. J Allergy Clin Immunol (2014) 134(5):1193-5.e4. doi: 10.1016/j.jaci.2014.07.029

119. Weidinger S, Beck LA, Bieber T, Kabashima K, Irvine AD. Atopic Dermatitis. Nat Rev Dis Primers (2018) 4(1):1. doi: 10.1038/s41572-018-0001-Z

120. Dong W, An J, Geng P, Zeng X, Chen Y, Zhao Z, et al. Years Lost Due to Disability From Skin Diseases in China 1990-2017: Findings From the Global
Burden of Disease Study 2017. J Dermatol (2020) 182(1):248-50. doi: 10.1111/bjd.18329

121. Leung DY, Boguniewicz M, Howell MD, Nomura I, Hamid QA. New Insights Into Atopic Dermatitis. J Clin Invest (2004) 113(5):651-7. doi: $10.1172 /$ jci2 1060

122. Salimi M, Barlow JL, Saunders SP, Xue L, Gutowska-Owsiak D, Wang X, et al. A Role for IL-25 and IL-33-driven Type-2 Innate Lymphoid Cells in Atopic Dermatitis. J Exp Med (2013) 210(13):2939-50. doi: 10.1084/ jem. 20130351

123. Imai Y. Interleukin-33 in Atopic Dermatitis. J Dermatol Sci (2019) 96(1):2-7. doi: 10.1016/j.jdermsci.2019.08.006

124. Imai Y, Yasuda K, Nagai M, Kusakabe M, Kubo M, Nakanishi K, et al. IL-33Induced Atopic Dermatitis-Like Inflammation in Mice is Mediated by Group 2 Innate Lymphoid Cells in Concert With Basophils. J Invest Dermatol (2019) 139(10):2185-94.e3. doi: 10.1016/j.jid.2019.04.016

125. Chen YL, Gutowska-Owsiak D, Hardman CS, Westmoreland M, MacKenzie T, Cifuentes L, et al. Proof-of-Concept Clinical Trial of Etokimab Shows a Key Role for IL-33 in Atopic Dermatitis Pathogenesis. Sci Transl Med (2019) 11(515):eaax2945. doi: 10.1126/scitranslmed.aax2945

126. Imai Y, Yasuda K, Sakaguchi Y, Haneda T, Mizutani H, Yoshimoto T, et al. Skin-Specific Expression of IL-33 Activates Group 2 Innate Lymphoid Cells and Elicits Atopic Dermatitis-Like Inflammation in Mice. Proc Natl Acad Sci USA (2013) 110(34):13921-6. doi: 10.1073/pnas.1307321110

127. Ryffel B, Alves-Filho JC. ILC2s and Basophils Team Up to Orchestrate IL-33Induced Atopic Dermatitis. J Invest Dermatol (2019) 139(10):2077-9. doi: $10.1016 /$ j.jid.2019.06.118

128. Halim TY, Hwang YY, Scanlon ST, Zaghouani H, Garbi N, Fallon PG, et al. Group 2 Innate Lymphoid Cells License Dendritic Cells to Potentiate Memory TH2 Cell Responses. Nat Immunol (2016) 17(1):57-64. doi: $10.1038 /$ ni.3294

129. Rafei-Shamsabadi DA, Klose CSN, Halim TYF, Tanriver Y, Jakob T. Context Dependent Role of Type 2 Innate Lymphoid Cells in Allergic Skin Inflammation. Front Immunol (2019) 10:2591. doi: 10.3389/fimmu. 2019.02591

130. Otsuka A, Nonomura Y, Kabashima K. Roles of Basophils and Mast Cells in Cutaneous Inflammation. Semin Immunopathol (2016) 38(5):563-70. doi: 10.1007/s00281-016-0570-4

131. Salimi M, Stöger L, Liu W, Go S, Pavord I, Klenerman P, et al. Cysteinyl Leukotriene E(4) Activates Human Group 2 Innate Lymphoid Cells and Enhances the Effect of Prostaglandin D(2) and Epithelial Cytokines. J Allergy Clin Immunol (2017) 140(4):1090-100.e11. doi: 10.1016/j.jaci.2016.12.958

132. Rafei-Shamsabadi DA, van de Poel S, Dorn B, Kunz S, Martin SF, Klose CSN, et al. Lack of Type 2 Innate Lymphoid Cells Promotes a Type I-Driven Enhanced Immune Response in Contact Hypersensitivity. J Invest Dermatol (2018) 138(9):1962-72. doi: 10.1016/j.jid.2018.03.001

133. Cole C, Kroboth K, Schurch NJ, Sandilands A, Sherstnev A, O’Regan GM, et al. Filaggrin-Stratified Transcriptomic Analysis of Pediatric Skin Identifies Mechanistic Pathways in Patients With Atopic Dermatitis. J Allergy Clin Immunol (2014) 134(1):82-91. doi: 10.1016/j.jaci.2014.04.021

134. Vávrová K, Henkes D, Strüver K, Sochorová M, Školová B, Witting MY, et al. Filaggrin Deficiency Leads to Impaired Lipid Profile and Altered Acidification Pathways in a 3D Skin Construct. J Invest Dermatol (2014) 134(3):746-53. doi: 10.1038/jid.2013.402

135. Saunders SP, Moran T, Floudas A, Wurlod F, Kaszlikowska A, Salimi M, et al. Spontaneous Atopic Dermatitis is Mediated by Innate Immunity, With the Secondary Lung Inflammation of the Atopic March Requiring Adaptive Immunity. J Allergy Clin Immunol (2016) 137(2):482-91. doi: 10.1016/ j.jaci.2015.06.045

136. Henry J, Hsu CY, Haftek M, Nachat R, de Koning HD, Gardinal-Galera I, et al. Hornerin is a Component of the Epidermal Cornified Cell Envelopes. FASEB J (2011) 25(5):1567-76. doi: 10.1096/fj.10-168658

137. Marenholz I, Rivera VA, Esparza-Gordillo J, Bauerfeind A, Lee-Kirsch MA, Ciechanowicz A, et al. Association Screening in the Epidermal Differentiation Complex (EDC) Identifies an SPRR3 Repeat Number Variant as a Risk Factor for Eczema. J Invest Dermatol (2011) 131 (8):1644-9. doi: 10.1038/jid.2011.90

138. Margolis DJ, Gupta J, Apter AJ, Ganguly T, Hoffstad O, Papadopoulos M, et al. Filaggrin-2 Variation is Associated With More Persistent Atopic 
Dermatitis in African American Subjects. J Allergy Clin Immunol (2014) 133 (3):784-9. doi: 10.1016/j.jaci.2013.09.015

139. Park HY, Kim CR, Huh IS, Jung MY, Seo EY, Park JH, et al. Staphylococcus Aureus Colonization in Acute and Chronic Skin Lesions of Patients With Atopic Dermatitis. Ann Dermatol (2013) 25(4):410-6. doi: 10.5021/ ad.2013.25.4.410

140. Silverberg JI. Comorbidities and the Impact of Atopic Dermatitis. Ann Allergy Asthma Immunol (2019) 123(2):144-51. doi: 10.1016/j.anai.2019.04.020

141. Howell MD, Kim BE, Gao P, Grant AV, Boguniewicz M, Debenedetto A, et al. Cytokine Modulation of Atopic Dermatitis Filaggrin Skin Expression. J Allergy Clin Immunol (2007) 120(1):150-5. doi: 10.1016/j.jaci.2007.04.031

142. Leung DY, Guttman-Yassky E. Deciphering the Complexities of Atopic Dermatitis: Shifting Paradigms in Treatment Approaches. J Allergy Clin Immunol (2014) 134(4):769-79. doi: 10.1016/j.jaci.2014.08.008

143. Buzney CD, Gottlieb AB, Rosmarin D. Asthma and Atopic Dermatitis: A Review of Targeted Inhibition of Interleukin-4 and Interleukin-13 as Therapy for Atopic Disease. J Drugs Dermatol (2016) 15(2):165-71.

144. Jensen JM, Pfeiffer S, Witt M, Bräutigam M, Neumann C, Weichenthal M, et al. Different Effects of Pimecrolimus and Betamethasone on the Skin Barrier in Patients With Atopic Dermatitis. J Allergy Clin Immunol (2009) 124(3 Suppl 2):R19-28. doi: 10.1016/j.jaci.2009.07.015

145. Sicherer SH, Sampson HA. Food Allergy: Epidemiology, Pathogenesis, Diagnosis, and Treatment. J Allergy Clin Immunol (2014) 133(2):291-307; quiz 8. doi: 10.1016/j.jaci.2013.11.020

146. Burton OT, Medina Tamayo J, Stranks AJ, Miller S, Koleoglou KJ, Weinberg EO, et al. IgE Promotes Type 2 Innate Lymphoid Cells in Murine Food Allergy. Clin Exp Allergy (2018) 48(3):288-96. doi: 10.1111/cea.13075

147. Johnston LK, Chien KB, Bryce PJ. The Immunology of Food Allergy. J Immunol (Baltimore Md 1950) (2014) 192(6):2529-34. doi: 10.4049/ jimmunol.1303026

148. Burton OT, Noval Rivas M, Zhou JS, Logsdon SL, Darling AR, Koleoglou KJ, et al. Immunoglobulin E Signal Inhibition During Allergen Ingestion Leads to Reversal of Established Food Allergy and Induction of Regulatory T Cells. Immunity (2014) 41(1):141-51. doi: 10.1016/j.immuni.2014.05.017

149. Tordesillas L, Goswami R, Benedé S, Grishina G, Dunkin D, Järvinen KM, et al. Skin Exposure Promotes a Th2-Dependent Sensitization to Peanut Allergens. J Clin Invest (2014) 124(11):4965-75. doi: 10.1172/jci75660

150. Noval Rivas M, Burton OT, Wise P, Charbonnier LM, Georgiev P, Oettgen HC, et al. Regulatory T Cell Reprogramming Toward a Th2-Cell-Like Lineage Impairs Oral Tolerance and Promotes Food Allergy. Immunity (2015) 42(3):512-23. doi: 10.1016/j.immuni.2015.02.004

151. Galand C, Leyva-Castillo JM, Yoon J, Han A, Lee MS, McKenzie ANJ, et al. IL-33 Promotes Food Anaphylaxis in Epicutaneously Sensitized Mice by
Targeting Mast Cells. J Allergy Clin Immunol (2016) 138(5):1356-66. doi: $10.1016 /$ j.jaci.2016.03.056

152. Chu DK, Llop-Guevara A, Walker TD, Flader K, Goncharova S, Boudreau JE, et al. IL-33, But Not Thymic Stromal Lymphopoietin or IL-25, is Central to Mite and Peanut Allergic Sensitization. J Allergy Clin Immunol (2013) 131 (1):187-200.e1-8. doi: 10.1016/j.jaci.2012.08.002

153. Lee JB, Chen CY, Liu B, Mugge L, Angkasekwinai P, Facchinetti V, et al. IL-25 and CD4(+) TH2 Cells Enhance Type 2 Innate Lymphoid Cell-Derived IL-13 Production, Which Promotes IgE-Mediated Experimental Food Allergy. JAllergy Clin Immunol (2016) 137(4):1216-25.e5. doi: 10.1016/j.jaci.2015.09.019

154. Chu DK, Mohammed-Ali Z, Jiménez-Saiz R, Walker TD, Goncharova S, Llop-Guevara A, et al. T Helper Cell IL-4 Drives Intestinal Th2 Priming to Oral Peanut Antigen, Under the Control of OX40L and Independent of Innate-Like Lymphocytes. Mucosal Immunol (2014) 7(6):1395-404. doi: $10.1038 / \mathrm{mi} .2014 .29$

155. Shik D, Tomar S, Lee JB, Chen CY, Smith A, Wang YH. IL-9-Producing Cells in the Development of IgE-Mediated Food Allergy. Semin Immunopathol (2017) 39(1):69-77. doi: 10.1007/s00281-016-0605-x

156. Chen CY, Lee JB, Liu B, Ohta S, Wang PY, Kartashov AV, et al. Induction of Interleukin-9-Producing Mucosal Mast Cells Promotes Susceptibility to IgEMediated Experimental Food Allergy. Immunity (2015) 43(4):788-802. doi: 10.1016/j.immuni.2015.08.020

157. Willits EK, Park MA, Hartz MF, Schleck CD, Weaver AL, Joshi AY. Food Allergy: A Comprehensive Population-Based Cohort Study. Mayo Clin Proc (2018) 93(10):1423-30. doi: 10.1016/j.mayocp.2018.05.031

158. Lack G, Fox D, Northstone K, Golding J. Factors Associated With the Development of Peanut Allergy in Childhood. N Engl J Med (2003) 348 (11):977-85. doi: 10.1056/NEJMoa013536

159. Dunkin D, Berin MC, Mayer L. Allergic Sensitization Can be Induced Via Multiple Physiologic Routes in an Adjuvant-Dependent Manner. J Allergy Clin Immunol (2011) 128(6):1251-8e2. doi: 10.1016/j.jaci.2011.06.007

Conflict of Interest: The authors declare that the research was conducted in the absence of any commercial or financial relationships that could be construed as a potential conflict of interest.

Copyright (c) 2021 Zheng, Zhang, Pan, Liu, Qin, Qiu, Liu and Wang. This is an open-access article distributed under the terms of the Creative Commons Attribution License (CC BY). The use, distribution or reproduction in other forums is permitted, provided the original author(s) and the copyright owner(s) are credited and that the original publication in this journal is cited, in accordance with accepted academic practice. No use, distribution or reproduction is permitted which does not comply with these terms. 